\title{
La Sanción por inexactitud en el Impuesto sobre la Renta en la jurisprudencia del Consejo de Estado 2000-2013
}

\author{
ANDRÉS Medina SAlazar*
}

\section{Consideraciones previas}

Los elementos que configuran el hecho generador de un tributo provienen del sistema normativo, pero la norma no basta para el nacimiento de la obligación tributaria, como quiera que resulta necesario que un sujeto pasivo específico incurra en los supuestos de hecho previstos para poder atribuirle tal consecuencia jurídica: la obligación tributaria.

Sin embargo, la obligación tributaria debe ser cuantificada con el propósito de establecer el monto respecto del cual la administración puede exigir la prestación consistente en el pago del gravamen, y es desde la perspectiva de quien determina el monto de la obligación que existen dos tipos de tributos: los de liquidación administrativa y los de autoliquidación.

Ahora bien, la liquidación de la obligación tributaria como procedimiento administrativo es el agregado de actos desarrollados en forma continua por la administración, con o sin el concurso de los sujetos pasivos, con el propósito de fijar en cada supuesto de realización del hecho generador la cuantía exacta del tributo, que termina con la expedición de un acto administrativo.
Desde la perspectiva de la liquidación realizada por el propio obligado o autoliquidación, nos encontramos en el cumplimiento de un deber formal por parte del sujeto pasivo, y por ende no dentro de un procedimiento administrativo; sin perjuicio de que efectivamente se trata también de un procedimiento, como quiera que es un conjunto de actos, cuyo propósito consiste en el señalamiento de la prestación a su cargo.

En los primeros -los impuestos de liquidación administrativa-, la administración es la competente para fijar desde el principio y a través de acto administrativo la cuantía exacta a cargo del sujeto pasivo; lo hace de oficio, cuando cuenta con la información necesaria para este cometido -la cual puede ser endógena o exógena-, o a solicitud de parte, en el supuesto de que la información provenga del contribuyente.

En este caso es la administración la que se encarga de interpretar el ordenamiento jurídico y de darle aplicación al caso particular.

Véase cómo en este supuesto la participación del sujeto pasivo se limita a poner en conocimiento de la administración determinados elementos de la obligación tributaria,

* Abogado. Especialista en Derecho Tributario y magíster en Derecho con énfasis en tributación de la Universidad Externado de Colombia. Docente de la misma casa de estudios. 
y a pagar la suma fijada a través de acto administrativo.

Por el contrario, para los segundos -impuestos de autoliquidación o declaración-, el mismo sujeto pasivo fija la suma de la que es deudor, en cumplimiento de un deber de carácter tributario. Es en este grupo de impuestos en el que se encuentra el Impuesto sobre la Renta y el Impuesto sobre la Renta para la Equidad -CREE.

En este caso, el sujeto pasivo no solo le informa a la administración tributaria cuál es la base gravable y la tarifa aplicable al supuesto fáctico que produjo el nacimiento de la obligación tributaria, sino que además interpreta y aplica el ordenamiento impositivo en la situación particular del señalamiento de su prestación a cargo; esta actividad se desarrolla en cumplimiento de un deber formal, comúnmente denominado en nuestro país como deber de declarar.

Este procedimiento de gestión tributaria resulta aplicable cuando el análisis del elemento objetivo - aspectos material, temporal, espacial y cuantitativo- del hecho generador se realiza sobre factores que obedecen a información propia del declarante, tal como es el caso del Impuesto sobre la Renta y el CREE.

En los impuestos de autoliquidación, la administración tributaria también tiene la posibilidad de fijar el monto de la obligación que corresponde, cuando desvirtúa lo señalado por el declarante en ejercicio de sus facultades de fiscalización, control y determinación o cuando precisa directamente la obligación a cargo, en el evento en que se omita el deber de declarar.

Partiendo del supuesto de que el sujeto pasivo cumple con el deber de declarar, ¿cómo lograr que la interpretación que ofrece del ordenamiento se ajuste al mismo, o por lo menos que siga el sentido fijado por la administración de impuestos o de la Jurisdicción de lo Contencioso Administrativo?

Al respecto conviene poner de presente que el sistema de gestión de los impuestos de autoliquidación en Colombia tiene una característica muy particular, que consiste en que el contribuyente no solo interpreta el ordenamiento jurídico para determinar el monto de la obligación tributaria a su cargo, sino que además es el llamado a interpretar ese ordenamiento para "autoimponerse" las sanciones.

La "autoimposición" de sanciones en materia tributaria fue avalada por la Corte Constitucional en la Sentencia C-506 de 2002, en la que, después de presentar una desordenada lluvia de ideas de por qué la DIAN como entidad administrativa es competente para imponer sanciones en el ámbito, concluye sin ningún argumento previo a propósito:

6. De todo lo anterior puede concluirse que las disposiciones acusadas, en cuanto se refieren a la imposición de sanciones administrativas por la DIAN o a la autoliquidación de las mismas por los contribuyentes, declarantes, responsables o agentes retenedores, son una manifestación concreta de la actividad sancionatoria de la Administración y no del ejercicio de funciones jurisdiccionales. Por ello no le asiste razón al demandante cuando afirma que el señalamiento por la ley de obligaciones de auto liquidar sanciones tributarias equivale a la atribución a los particulares del ejercicio de funciones jurisdiccionales en desconocimiento de la Constitución, que sólo tolera esta posibilidad cuando los particulares actúan transitoriamente como árbitros o conciliadores (C.P art. 116). 
Para el autor de este documento, el error de la Corte es de tal magnitud que impone dos conclusiones posibles: o bien el magistrado ponente Monroy Cabra no entendió de qué se trataba el tema, o fue una maniobra deliberada para evitar abordar el análisis de un tema tan complejo e indefendible, que terminaba con la inconstitucionalidad del sistema de autoimposición de sanciones en el ámbito tributario.

Así las cosas, cuando el contribuyente sabe o detecta que su declaración tributaria presenta inconsistencias y errores que ameritan enmendarse, tiene la posibilidad de corregir voluntariamente su autoliquidación en los términos del artículo 644 del ET.

Si el sujeto pasivo de manera voluntaria corrige su declaración, y esta corrección arroja un mayor valor a pagar o un menor saldo a favor, la sanción que se autoaplicará será la sanción de corrección equivalente al $10 \%$ sobre esta suma, siempre que se realice antes de que la administración tributaria lo emplace para corregir, toda vez que si es emplazado el porcentaje aplicable será el $20 \%$ sobre la misma base.

Si el contribuyente decide no corregir la declaración con ocasión de un emplazamiento o incluso sin la existencia de éste, como quiera que se trata de un acto administrativo potestativo, el paso siguiente para la administración será la expedición de un requerimiento especial, que es un acto administrativo de trámite que contiene una propuesta acabada de modificación de la autoliquidación. En éste se propondrá una sanción por inexactitud del $160 \%$, y no una sanción por corrección del $20 \%$. Ahora bien, si el contribuyente decide corregir la declaración de "forma voluntaria" con motivo del requerimiento, la sanción por inexactitud se reduce a la cuarta parte, es decir, al $40 \%$ del mayor valor a pagar o menor saldo a favor.

Con el desarrollo anterior, se quiere poner de presente cómo en la medida en que el grado de participación de la administración en la corrección de las declaraciones aumenta, también aumenta el porcentaje de la sanción, llegando incluso a modificarse la sanción aplicable, al pasar de sanción de corrección o sanción por inexactitud.

De acuerdo con lo anotado, debe tenerse en cuenta que la sanción por inexactitud es liquidada, propuesta e impuesta por la administración de impuestos ante la negativa del contribuyente a corregir una declaración; en este orden de ideas, esta sanción no resultará aplicable a los impuestos de liquidación oficial, sino exclusivamente a los de autoliquidación.

Es por todo lo anterior que la sanción por inexactitud constituye el principal instrumento represivo con que cuenta la administración tributaria, en orden a ajustar al ordenamiento jurídico y a las posiciones administrativas el comportamiento de los sujetos pasivos desplegado en las autoliquidaciones o declaraciones tributarias, como quiera que la misma será equivalente al $160 \%$ de la diferencia entre el saldo a pagar o saldo a favor, según el caso, determinado en la liquidación oficial, y el declarado por el contribuyente o responsable, sin perjuicio, de las reducciones y los porcentajes especiales establecidos expresamente.

La sanción por inexactitud se encuentra prevista en el artículo 647 del Estatuto Tributario Nacional; la extensión de la norma obedece a la necesidad de cubrimiento de todas las infracciones posibles en el Impuesto sobre la Renta, los cuales obedecen a indicadores de capacidad contributiva diversos y a aspectos materiales disímiles. 
La norma, vigente a partir del año 2013, tiene los siguientes apartados aplicables al Impuesto Sobre la Renta, aunque en la redacción de la misma se evidencia la intención de ser un instrumento de control diseñado para este impuesto:

Artículo 647. Sanción por inexactitud. Constituye inexactitud sancionable en las declaraciones tributarias, la omisión de ingresos, de impuestos generados por las operaciones gravadas, de bienes o actuaciones susceptibles de gravamen, así como la inclusión de costos, deducciones, descuentos, exenciones, pasivos, impuestos descontables, retenciones o anticipos, inexistentes, y, en general, la utilización en las declaraciones tributarias, o en los informes suministrados a las Oficinas de Impuestos, de datos o factores falsos, equivocados, incompletos o desfigurados, de los cuales se derive un menor impuesto o saldo a pagar, o un mayor saldo a favor para el contribuyente o responsable [...].

La sanción por inexactitud será equivalente al ciento sesenta por ciento $(160 \%)$ de la diferencia entre el saldo a pagar o saldo a favor, según el caso, determinado en la liquidación oficial, y el declarado por el contribuyente o responsable. Esta sanción no se aplicará sobre el mayor valor del anticipo que se genere al modificar el impuesto declarado por el contribuyente.

[...]

La sanción por inexactitud a que se refiere este artículo, se reducirá cuando se cumplan los supuestos y condiciones de los artículos 709 y 713 .

No se configura inexactitud, cuando el menor valor a pagar que resulte en las decla- raciones tributarias, se derive de errores de apreciación o de diferencias de criterio entre las Oficinas de impuestos y el declarante, relativos a la interpretación del derecho aplicable, siempre que los hechos y cifras denunciados sean completos y verdaderos.

Parágrafo. Las inconsistencias en la declaración del impuesto de renta y complementarios derivadas de la información a que hace referencia el parágrafo 1o del artículo 50 de la Ley 789 de 2002 sobre aportes a la seguridad social será sancionable a título de inexactitud, en los términos del presente Estatuto Tributario.

El contenido del artículo 647 del E.T. es susceptible de ser dividido en dos partes: la primera, en la que se prevé específicamente a qué corresponde la inexactitud sancionable (omisión -de ingresos, de impuestos generados por las operaciones gravadas, de bienes o actuaciones susceptibles de gravamen-, inclusión -de costos, deducciones, descuentos, exenciones, pasivos, impuestos descontables, retenciones o anticipos, inexistentes- en las declaraciones tributarias), y la segunda, en la que se consagra una suerte de cláusula general, mediante la cual es sancionable la utilización de datos o factores falsos, equivocados, incompletos o desfigurados. Estos dos apartados están caracterizados por un supuesto común, y es que el comportamiento desplegado por el sujeto pasivo derive en un menor impuesto a pagar o mayor saldo a favor en lo que respecta con el Impuesto sobre la Renta.

En relación con el tipo establecido en el artículo 647, resulta posible afirmar que con suficiente precisión se puede saber qué es un costo, deducción y demás conceptos arriba señalados; empero, ¿cómo determina el 
operador jurídico la inexistencia?, ¿realidad económica de la operación o cumplimiento de requisitos legales? Ya tendremos oportunidad de ver qué entiende el Consejo de Estado al respecto.

La segunda parte de la norma, como quiera que se trata de un tipo de cobertura, la cantidad de supuestos sancionados puede generar algún grado de incertidumbre, porque, por ejemplo ¿qué puede entenderse por la utilización en las declaraciones tributarias de datos o factores falsos, equivocados, incompletos o desfigurados? La respuesta que ofreció la Corte Constitucional en la Sentencia C-571 de 2010 fue, en términos gruesos, lo que debe entenderse en este caso es eso, la utilización en las declaraciones tributarias de datos ofactores falsos, equivocados, incompletos o desfigurados.

Es necesario explicar el párrafo anterior: la Corte presenta en esta sentencia cuestionables argumentos para declarar la exequibilidad de la norma, entre los que se encuentran: (i) equipara la redacción del hecho generador de los impuestos con las sanciones en materia tributaria, reafirmando la creencia de que los impuestos son sanciones; (ii) hace afirmaciones vacías según las cuales el legislador no viola los principios de legalidad y de seguridad jurídica al emplear en normas sancionatorias de carácter tributario, expresiones que tengan un "grado de indeterminación aceptable constitucionalmente", porque una norma legal de carácter tributario es inexequible si da lugar a "dificultades de interpretación insuperables" -eso es cierto, las tributarias, no las sancionatorias-; (iii) señala que el uso de las expresiones acusadas no implica una violación al principio de legalidad ni promueve una situación de inseguridad jurídica que abra espacio a las arbitrariedades, y (iv) la aplicación de los principios constitucionales que rigen el derecho sancionatorio no se aplican con el celo y el rigor con el que se aplican cuando las normas analizadas contemplan sanciones de tipo penal.

Después de ese desgaste argumentativo, la Corte Constitucional llega a una conclusión bastante lógica, según la cual las expresiones "datos o factores falsos, equivocados, incompletos o desfigurados", presentes en el artículo 647 del E.T. tienen un grado de claridad y certeza, cuando son interpretadas dentro del contexto y las prácticas en las que estas normas se inscriben, toda vez que "son expresiones que en un contexto legal o cotidiano tienen usos y significados estandarizados". No obstante lo anterior, en lo que sí se equivoca la Corte es en que "No se trata de expresiones vagas y ambiguas, que den un amplio margen de decisión a los operadores jurídicos". Porque ingenuamente considera este tribunal que "En el contexto de derecho tributario hacen referencia a situaciones en las que la información otorgada por los contribuyentes a la administración de impuestos, relacionada con su actividad económica, no coincide con la realidad, es decir cuando se da una información contraria a la realidad, que no la refleja completamente, o que la altera".

En el siguiente apartado se tendrá la oportunidad de ver cómo el margen de interpretación y de aplicación de la sanción por inexactitud es muy amplio, lo que se reflejará en los cambios del derrotero jurisprudencial del Consejo de Estado.

Ahora bien, de acuerdo con lo previsto en el inciso 6 del artículo 647 del ET, "no se configura inexactitud, cuando el menor valor a pagar que resulte en las declaraciones tributarias, se derive de errores de apreciación o de diferencias de criterio entre las Oficinas 
de impuestos y el declarante, relativos a la interpretación del derecho aplicable, siempre que los hechos y cifras denunciados sean completos y verdaderos".

Este apartado normativo prevé o incorpora el error de prohibición del Derecho Penal, que constituye una causal de exoneración de la responsabilidad penal, en específico excluyente de la culpabilidad. El error de prohibición se ubica en la culpabilidad, como se afirmó, y hace referencia a la conciencia de la antijuridicidad del comportamiento; así las cosas, para que se verifique la exoneración de responsabilidad, la persona que sabe que está realizando un determinado comportamiento debe considerar que el mismo no es una infracción al ordenamiento y esta creencia debe ser invencible.

El error de prohibición tiene dos posibilidades: (i) Vencible, cuando el sujeto con un poco más de atención hubiera podido advertir que su comportamiento vulnera el ordenamiento jurídico-, caso en el cual sí hay responsabilidad pero se atenúa la pena; (ii) Invencible, cuando no existía forma de percatarse de la contravención, caso en el cual no hay responsabilidad.

De acuerdo con lo anterior, el inciso 6 del artículo 647 hace que la responsabilidad sancionatoria en materia tributaria por inexactitud sea subjetiva, el único tipo de responsabilidad admisible en un Estado de Derecho.

Este contenido normativo somete al operador jurídico de la administración tributaria a un ejercicio previo a la insinuación respecto de la procedencia de la sanción por inexactitud, el cual consiste en establecer si la diferencia en el monto a pagar-base sobre la cual se liquida la sanción por inexactitud-, deuda tributaria, que resulta de lo plasmado en la declaración presentada por el suje- to pasivo y lo fijado por la administración tributaria, tiene origen en errores de apreciación o en diferencias de criterios entre el resultado de la interpretación acogido por la administración y las otras interpretaciones posibles realizadas por el sujeto pasivo, que obedezcan a una razonable lectura del contenido normativo aplicado al caso concreto.

Aunado a lo anterior, no puede dejarse de lado la evaluación administrativa previa del requisito objetivo del inciso final para la no configuración de la inexactitud, consistente en que los hechos y cifras consignados en la declaración tributaria sean completos y verdaderos.

Los anteriores apartes evidencian, al rompe, la complejidad sustantiva que representa la aplicación de la sanción por inexactitud, porque pese a lo que señale el Consejo de Estado en algunas de sus providencias, un precepto siempre tendrá varios contenidos normativos dependiendo del resultado de la interpretación.

En este momento resulta relevante exponer la posición de la Corte Constitucional, la cual se produjo con motivo del juicio de constitucionalidad que se adelantó del artículo 647 del E.T. en la sentencia C- 916 de 1999 con ponencia de Fabio Morón Díaz, pronunciamiento que tuvo como ratio decidendi lo que a continuación se trascribe:

... este se limita a consagrar una causal de inculpabilidad que exonera de sanción tributaria, al tipificar las hipótesis en las que no se configura inexactitud sancionable en las declaraciones tributarias, lo que, en sentir de la Corporación, constituye cabal expresión del debido proceso y de la igualdad, al prever la regulación normativa en estudio, un trato diferenciado para el contribuyente cuya declaración arroja un menor 
valor a pagar, que se origina en diferencias interpretativas con la DIAN, pues, debiendo prevalecer el criterio jurídico de esta, como autoridad doctrinaria en materia de normas tributarias, no sería justo ni razonable que tal diferencia, en la hipótesis en comento, le acarreara una sanción.

Sin perjuicio de lo anterior, y para realizar un análisis de la jurisprudencia del Consejo de Estado, que es la corporación que decide la legalidad de los actos administrativos en última instancia, procedemos a hacer una transcripción de la ratio decidendi de los fallos en los que se ha pronunciado en relación con la procedencia o no de la sanción inexactitud, para concluir con los derroteros trazados, que en todo caso deben ser tenidos en cuenta por quienes tienen a su cargo la toma de decisiones en el ámbito tributario, ya sea en calidad de sujetos pasivos, administradores públicos de impuestos y la rama judicial. En este contexto se tienen las siguientes sentencias expedidas por la Sección Cuarta del Consejo de Estado:

\section{Relación de las sentencias del Consejo de Estado en relación con la sanción por inexactitud en el Impuesto sobre la $\operatorname{Renta}^{1}$}

Este apartado es necesario iniciarlo con advertencias de orden metodológico, para delimitar el alcance de las providencias que se presentan.

Se identificarán las sentencias por la fecha de expedición, el número del expediente y los apellidos del magistrado ponente; luego se señalará si resulta procedente o no la imposición de la sanción con un simple sí o no entre paréntesis. Después de identificada la sentencia se transcribe el aparte que se considera como la ratio decidendi del caso.

Las providencias seleccionadas obedecen exclusivamente a la sanción por inexactitud en el Impuesto sobre la Renta, lo que resulta fundamental, como quiera que no se incorporan fallos en relación con otros impuestos.

El periodo que se tiene en cuenta en este análisis es 2000-2013 (primer bimestre).

La presentación de las sentencias se hace de la más reciente a la más antigua.

\section{8 de febrero de 2013. Rad. 18485. Ortiz de Rodríguez (Sî)}

Como en el presente caso se encuentra demostrado que el contribuyente solicitó la compensación de unas pérdidas que fueron trasladadas en desconocimiento de la prohibición contemplada en el artículo 147 del Estatuto Tributario, resulta procedente la imposición de la sanción por inexactitud. Para la Sala, es claro que no se presentó diferencia de criterios en relación con la interpretación del derecho aplicable, porque el artículo 147 ibídem de manera expresa prohíbe que las pérdidas fiscales puedan ser trasladas por la sociedad a sus socios. En ese sentido, al no haberse comprobado que la interpretación de las normas lo haya inducido a apreciarlas de manera errónea, se mantendrá la sanción por inexactitud impuesta en los actos acusados.

\footnotetext{
${ }^{1}$ Para la preparación de este capítulo se tomó la relación de sentencias contenida en el CD de junio de 2013 de Derecho Tributario del Banco de Datos Jurídicos de la Universidad Externado de Colombia.
} 
28 de febrero de 2013. Rad. 18807. Briceño de Valencia (Sí)

En cuanto a la sanción por inexactitud impuesta, la Sala advierte que el Estatuto Tributario en el artículo 647 incluye como hecho sancionable que el contribuyente haya omitido ingresos que debió incluir en la declaración tributaria de los cuales derivó un "menor impuesto o saldo a pagar o un mayor saldo a favor". En la investigación adelantada, la administración constató que el mayor saldo a favor determinado por la sociedad en la declaración objeto de la modificación oficial se debió a que el contribuyente aplicó indebidamente el procedimiento especial de determinación de los ingresos previsto en el artículo 10 de la Ley 26 de 1989, al que no tenía derecho y, aumentó el saldo a favor que luego solicitó en devolución. Como quedó dilucidado, tal normativa no se aplica a los distribuidores minoristas de GLP. Así, lo que se presenta, en el caso, es el desconocimiento de la norma aplicable, pues si no es beneficiario del procedimiento especial, debe declarar conforme al sistema ordinario de depuración de la renta, previsto en el artículo 26 del Estatuto Tributario. Al aplicar indebidamente la disposición especial, los ingresos informados en el denuncio tributario fueron inferiores a los verificados por los funcionarios de la administración, situación que pone en evidencia la ocurrencia del hecho sancionable, esto es, la omisión de ingresos. Además, de la utilización indebida de la norma, obtuvo un menor impuesto y un mayor saldo a favor, supuestos legales que dan lugar a imponer la sanción discutida. De otra parte, no es aceptable confundir el desconocimiento de un precepto legal con la alegada diferencia de criterios en la interpretación del derecho aplicable.
1 de noviembre de 2012. Rad. 17786. Bastidas Bárcenas (Sí)

La demandante alega que en el caso concreto se presentó una diferencia de criterios con la autoridad tributaria sobre la interpretación del artículo 107 del Estatuto Tributario. La Sala no advierte que se haya presentado esa controversia. Por el contrario, las partes tienen claro en qué consisten los criterios de necesidad, proporcionalidad y de relación de causalidad. La discrepancia ocurrió por la valoración de los hechos que para la demandante justificaban la declaración de las deducciones, valoración fáctica que, como se precisó, es distinta de la interpretación estricta del derecho aplicable. Por lo tanto, la Sala reliquidará la sanción sobre las expensas que fueron rechazadas como deducibles, pues fueron incluidas de manera improcedente en el denuncio de renta, lo que dio lugar a una menor liquidación del impuesto de renta.

\section{1 de noviembre de 2012. Rad. 18109.} Bastidas Bárcenas (Sí)

Ahora bien, para que se perfeccione la infracción, la inclusión se ejecuta para cumplir un único propósito: reportar datos inexistentes para obtener un provecho que se traduce en el menor pago de impuestos o en la determinación de un mayor saldo a favor. El adjetivo inexistente debe entenderse en sus dos acepciones: como adjetivo relativo a aquello que carece de existencia, y como adjetivo relativo a aquello que, si bien existe, se considera totalmente nulo, porque es "Falto de valor y fuerza para obligar o tener efecto, por ser contrario a las leyes, o por carecer de las solemnidades que se requieren en la sustancia o en el modo.” De ahí que el artículo 
647 ibídem prevea que, en general, lo que se quiere sancionar es la utilización en las declaraciones tributarias, o en los informes suministrados a las Oficinas de Impuestos, de datos o factores falsos, equivocados, incompletos o desfigurados, puesto que todos estos adjetivos, en últimas, implican la inexistencia de los egresos que se llevan como costo, deducción, descuento, exención, pasivo, impuesto descontable, retención o anticipo, sin serlo, por una de las siguientes razones: o porque en realidad no existen esos egresos; o porque, aun existiendo, no se probaron; o porque, aún probados, no se subsumen en ningún precepto jurídico del Estatuto Tributario que les dé valor y fuerza para tener el efecto invocado, por carecer de las solemnidades que exige ese Estatuto Tributario para darles la calidad de tales, a menos que, en este último caso se verifique la interpretación errónea de la norma por parte del contribuyente, que lo haya inducido a subsumir los hechos económicos declarados en la misma.

Para la Sala, cuando el artículo 647 citado se refiere a la interpretación del derecho aplicable, claramente se refiere a "la interpretación del derecho propiamente dicha" a que alude la cita referida. El artículo 647 no se refiere a la interpretación de los hechos. Por eso, no es posible exonerar de la sanción por inexactitud cuando el menor valor a pagar que resulte en las declaraciones tributarias se derive de errores de hecho. Por interpretación errónea, la Sala Plena ha precisado que "consiste en aplicar la disposición pertinente a la controversia, pero dándole un sentido y alcance que no tiene; se sitúa siempre en un error de hermenéutica jurídica".

Ahora bien, identificar cuándo se está en presencia de un error de hermenéutica jurídica no es tarea fácil, pero sirve como pauta identificar la metodología y las pautas legales y de doctrina judicial utilizadas por el contribuyente para arribar a la interpretación que lo indujo a declarar de determinada manera las cargas tributarias. De tal manera que cuando el menor valor a pagar se derive de los errores de derecho en que incurra el contribuyente por indebida interpretación, el artículo 647 del E.T. exige que "los hechos y cifras denunciados sean completos y verdaderos". De manera que, así se advierta el "error de interpretación" que indujo al contribuyente a incluir en la declaración tributaria correspondiente erogaciones a título de costos, deducciones, descuentos, exenciones, pasivos, impuestos descontables, retenciones o anticipos, el contribuyente no está exonerado de probar la existencia de los hechos y cifras que declaró, pues ante la ausencia de esa prueba, igual se aplicará la sanción. No debe perderse de vista que las dudas provenientes de vacíos probatorios solo se resuelven a favor del contribuyente cuando no hay modo de eliminarlas, y siempre y cuando el contribuyente no se encuentre obligado a probar determinados hechos. Analizado el caso concreto, la Sala advierte que no se presentó ninguna diferencia de criterios entre la DIAN y la parte actora, única circunstancia especial que regula el artículo 647 del E.T. para eximir al contribuyente de la sanción por inexactitud. Por el contrario, se evidencia que la discusión se centró en la interpretación de los hechos y pruebas que fundamentaron las glosas que propuso la DIAN en los actos administrativos demandados. Lo anterior evidencia que la DIAN adicionó ingresos y rechazó costos y gastos deducibles por la falta de contabilización y/o por la ausencia de prueba idónea de la operación que los originaba. Estas conductas son sancionables en los términos del artículo 
647 del Estatuto Tributario, pues la Clínica omitió declarar ingresos y, adicionalmente, incluyó gastos y costos que no pudo probar o que incluyó sin cumplir los requisitos legales para su procedencia.

\section{1 de noviembre de 2012. Rad. 18329. Ortiz de Rodríguez (Sî)}

En coincidencia con el concepto del Ministerio Público y con la posición del Tribunal, no acepta la Sala el carácter sancionatorio de la comparación patrimonial. Esta es, según el artículo 236 ya citado, un sistema especial de determinación de la renta líquida gravable basado en la presunción legal de que toda diferencia positiva entre el patrimonio líquido del período gravable y de aquel inmediatamente anterior no explicado por las rentas (gravables y exentas) y las ganancias ocasionales es capitalización de rentas, por lo que debe tomarse como tal y servir de base para liquidar el correspondiente impuesto.

Es un sistema especial, paralelo al de depuración ordinaria descrito en el artículo 26 del Estatuto Tributario o al de renta presuntiva contenido en el artículo $188 \mathrm{ib}$. para efectos de fijar el tope inferior de la renta líquida. No sanciona sino permite al Estado contar con un procedimiento de reajuste de los factores de cálculo del impuesto de renta a fin de acercar las bases gravables de recaudación a la realidad financiera y de operaciones de los contribuyentes.

Por tanto no hay dos sanciones; la única sanción aplicada en el presente procedimiento es la de inexactitud. En consecuencia no existe incompatibilidad alguna entre la aplicación de esta sanción y la comparación patrimonial ni viola los derechos consagrados en el artículo 29 de la Carta Política. Adicionalmente, la sanción por inexactitud es procedente a la luz del artículo 647 del Estatuto Tributario, pues se ha presentado la inclusión de pasivos no probados y de datos equivocados de los cuales se derivó un menor impuesto a pagar.

\section{1 de octubre de 2012. Rad.18233. Ortiz de Rodríguez (Sî)}

Así mismo, puntualizó que la interpretación del derecho aplicable a la que alude el inciso final del artículo 647 del E.T., corresponde a la "interpretación del derecho propiamente dicha" y no a la de los hechos discutidos, aclarando que, a la luz del criterio de la Sala Plena de esta Corporación, la interpretación errónea consiste en aplicar la disposición pertinente a la controversia, pero dándole un sentido y alcance que no tiene, de modo que siempre se sitúa en un error de hermenéutica jurídica.

No obstante, en la interpretación del artículo 158-3 del E.T. no se advierten ese tipo de errores ni ninguna otra característica de las diferencias de criterio que exoneran el efecto sancionador, porque la norma es lo suficientemente clara en cuanto a la exclusividad de la deducción especial del 30 por ciento para la inversión en activos fijos reales productivos adquiridos y no para la negociación de bienes con expectativa de adquisición formal, como los prometidos en venta. Así pues, se concluye que la discusión motivante de la controversia objeto de la presente litis se reduce al mero desconocimiento de la norma legal que consagra la deducción señalada y que, por lo tanto, la sanción por inexactitud debe mantenerse. En consecuencia, se revocará la sentencia apelada para disponer lo pertinente de acuerdo con las conclusiones logradas en esta instancia. 
7 de junio de 2012. Rad. 18151. Giraldo Giraldo (Sî)

En el presente caso, la discusión existente se centra en el tratamiento que le dio el contribuyente a los egresos originados en la amortización de desfase Bancoop y en gastos del Consejo Directivo. Como anteriormente se observó, el contribuyente no demostró que las expensas tuvieran relación de causalidad con los ingresos de la entidad, además, que estuvieran de acuerdo con la legislación cooperativa vigente. En consecuencia, al encontrarse demostrado que la actora incluyó deducciones sin el cumplimiento de los requisitos de procedencia que establece el régimen tributario especial para el caso de las cooperativas, y al no haberse comprobado que la interpretación de las normas la haya inducido a apreciarlas de manera errónea, se mantendrá la sanción por inexactitud impuesta en los actos acusados.

\section{0 de mayo de 2012. Rad.17450. Bastidas Bárcenas (Sî)}

Ahora bien, el artículo 647 del E.T. señala que no habrá lugar a imponer sanción por inexactitud cuando el menor valor a pagar devenga de errores de apreciación o diferencias de criterio relativos al derecho aplicable... El alcance de esta aparte normativo ha sido precisado por la Sala quien ha señalado que la discrepancia entre el fisco y la contribuyente debe consistir en una argumentación sólida que aunque equivocada, permita concluir que su interpretación en cuanto al derecho aplicable le permitió creer que su actuación estaba amparada legalmente y no cuando se presentan argumentos que a pesar de su apariencia jurídica carecen de fundamento objetivo y razonable. Así mismo, tiene por establecido que cuando el artículo 647 del E.T. se refiere a la interpretación del derecho aplicable, claramente se refiere a "la interpretación del derecho propiamente dicha" a que hace alusión la cita referida, lo que excluye la interpretación sobre los hechos discutidos. Ahora bien, por interpretación errónea, la Sala Plena ha precisado que esta consiste en aplicar la disposición pertinente a la controversia, pero dándole un sentido y alcance que no tiene; es decir, que se sitúa siempre en un error de hermenéutica jurídica. Por lo expuesto, en tanto que la litis giró en torno a la indebida aplicación del artículo 24 de la Ley 788 de 2002 y a la falta de aplicación del artículo 84 de la Ley 75 de 1986, mas no a la indebida interpretación de ninguna de estas dos normas, la Sala considera que la sanción por inexactitud es procedente.

\section{1 de marzo de 2012. Rad.17432. Bastidas Bárcenas (Sî)}

En cuanto a la diferencia de criterios entre la DIAN y la parte actora, si bien para la Sala es incuestionable que se ha presentado una polémica respecto a la naturaleza jurídica que tiene la compensación monetaria por vacaciones, en cuanto a si tiene o no el carácter indemnizatorio, esa discusión era irrelevante para efectos de determinar si es deducible o no la compensación.

Lo relevante siempre ha sido establecer si la compensación monetaria es deducible al tenor del artículo 108 del E.T., habida cuenta de que esta norma alude a la deducción por salarios y al descanso remunerado. Para el demandante, se reitera, la compensación monetaria por vacaciones sí es deducible al tenor del artículo 108 del E.T., pero sin que el contribuyente tenga que acreditar el pago de los aportes parafiscales. 
Esa interpretación la fundamentó en que, a su juicio, gramaticalmente, no es lo mismo el descanso remunerado que la compensación monetaria por vacaciones, porque precisamente en este último caso no se disfruta del descanso, presupuesto sine qua non previsto en las normas laborales y de función pública, para el primer evento. Esa interpretación no tiene una justificación razonable, puesto que elude lo odioso de la disposición (pago de aportes parafiscales) y acoge, únicamente, lo favorable que se deriva de la misma (es deducible).

De haberse aceptado que la compensación monetaria por vacaciones no es equivalente al descanso remunerado, como lo sugirió la parte actora, necesariamente se habría llegado a la conclusión de que dicha compensación tampoco era deducible por no estar regulada en el artículo 108 del E.T., discriminación que, para la Sala, se insiste, no tiene justificación razonable alguna. Por eso, el análisis que propuso la parte actora en la vía administrativa como en la judicial no se cimentó en criterios de hermenéutica jurídica que permitan concluir que, en el presente caso, se presentó una diferencia razonable de criterios. No prospera el cargo.

\section{9 de febrero de 2012. Rad. 18249. Briceño de Valencia (Sí)}

No demostró las retenciones en la fuente incluidas en la declaración de renta. De acuerdo con lo anterior, la Sala advierte que en el caso concreto no existe una diferencia de criterio entre el contribuyente y la Administración. Por el contrario, lo que se advierte es que la parte actora no cumplió con la carga de la prueba que le corresponde al pretender hacer valer en su favor un derecho, razón más que suficiente para confirmar la sanción por inexactitud, pero solo en relación con la suma respecto de la cual se mantiene el rechazo.

\section{6 de diciembre de 2011. Rad. 18368. Briceño de Valencia (Sí)}

En criterio de la Sala, para cuantificar la sanción de inexactitud debió incluirse el valor de la sobretasa toda vez que hace parte del impuesto de renta, porque, es sobre el valor del impuesto a cargo que se liquidaba la sobretasa según el artículo 29 de la Ley 788 de 2002, sin que le asista razón al contribuyente para no tenerla en cuenta. Por ello, pierde importancia el argumento de la actora de que el impuesto a cargo se haya liquidado previo uso del método de la renta presuntiva, por cuanto, el asunto en discusión, radica en establecer si sobre el valor de la sobretasa dejada de liquidar y que hace parte del impuesto de renta procede o no la sanción de inexactitud. El artículo 647 del Estatuto Tributario establece la sanción de inexactitud, cuando la conducta del contribuyente se dirija a obtener el "pago de un menor impuesto", como efectivamente ocurrió al dejar liquidar el valor de la sobretasa, sin que pueda aducirse diferencia de criterios porque la demandante estaba obligada para el año 2003 a liquidar dicho "recargo" en su declaración de renta, sin que obre norma o doctrina jurisprudencial del Consejo de Estado que le excusare de tal obligación y que, en todo caso, la interpretación del derecho hecha por la actora sea razonable o justificada, y en consecuencia, no se levantara la sanción de inexactitud.

\section{5 de diciembre de 2011. Rad. 18341. Briceño de Valencia (Sî)}

En consideración a que se encontró improcedente la exención del beneficio neto o ex- 
cedente obtenido por la parte actora en el año gravable 1997 e incluido en la declaración de renta del año 1998, es del caso referirse a la sanción por inexactitud impuesta en los actos administrativos demandados, sobre la cual, es oportuno señalar que el Tribunal no hizo pronunciamiento expreso en la sentencia, precisamente por haber accedido a las pretensiones de la demanda. Conforme con lo anterior, y teniendo en cuenta que en el presente asunto la parte actora no comprobó el cumplimiento de los requisitos previstos en la norma para la procedencia de la exención sobre el beneficio neto o excedente determinado por la cooperativa por el año 1997, es decir, no cumplió con la carga de la prueba que le corresponde al pretender hacer valer en su favor un beneficio, la sanción por inexactitud resulta procedente, pero solo en relación con la suma respecto de la cual se mantiene el rechazo.

\section{7 de noviembre de 2011. Rad. 18100. Briceño de Valencia (Sí)}

Por último y en relación con la sanción por inexactitud prevista en el artículo 647 del Estatuto Tributario, si bien la Sala había considerado de manera reiterada que ni por controversias de interpretación, ni por falta de pruebas era pertinente aplicar la sanción, la jurisprudencia reciente de esta Sección ha señalado que la falta de prueba sobre la realidad y procedencia de las partidas declaradas no es motivo para no aplicar la sanción por inexactitud.

En efecto, la Sala en sentencia del 28 de junio de 2010 consideró que la falta de prueba sobre la realización de los costos, significaba la inclusión en la declaración de costos inexistentes que daban lugar a un menor impuesto a pagar, conducta que era sancio- nable en virtud del artículo 647 del Estatuto Tributario.

Así mismo, mediante sentencia del 19 de agosto de 2010, la Sala indicó que generaba la sanción por inexactitud la conducta del contribuyente de incluir en la declaración, como deducciones, partidas frente a las cuales no se demostró su realidad y procedencia, que afectaron la base gravable y dieron lugar a un menor impuesto a cargo.

En esa oportunidad advirtió que no era necesario que la Administración estableciera que los gastos fueron irreales, pues lo cierto era que fueron solicitados como deducción, sin demostrar su procedencia; máxime cuando correspondía al contribuyente desvirtuar la presunción de legalidad de los actos administrativos. En efecto, para que una partida declarada se tenga como real y verdadera, a juicio de la Sala, como regla general, debe probarse la realización de la misma, que existe, que fue efectuada y de ahí que se pueda probar que se configuraron los supuestos de hecho que la norma consagra.

Es decir, requiere de una actividad probatoria suficiente y adecuada sobre la existencia de esos hechos que originan la partida. La sanción no tiene como condición que se evidencie una conducta evasiva o fraudulenta por parte del contribuyente, pero sí se requiere que los datos declarados sean reales. Por consiguiente, en el presente caso la sanción por inexactitud debe mantenerse únicamente respecto del valor cuyo rechazo se mantiene, porque la deficiencia probatoria no exonera de su imposición.

\section{7 de octubre de 2011. Rad. 17115. Bastidas Bárcenas (Sî)}

Aplicando los anteriores criterios al caso concreto se tiene que sí se configuró la 
sanción por inexactitud, en todas las glosas, salvo en la referida a la destrucción de inventarios por \$4.000.000.000, porque: - En el caso concreto está probado que la parte actora incluyó en el denuncio rentístico objeto de la liquidación oficial deducciones inexistentes. - Las deducciones son inexistentes porque la parte actora las declaró como deudas manifiestamente perdidas y sin valor, cuando en realidad no lo eran. - Como no se probó el hecho económico declarado en el denuncio privado objeto de liquidación oficial, ese hecho económico no podía estar subsumido en el artículo 146 del E.T. referido a las deducciones por deudas manifiestamente perdidas y sin valor. - En esa medida, la controversia nunca giró en torno a la interpretación del artículo 146 del E.T. Por lo tanto, nunca se presentó una errónea apreciación del derecho o de diferencias de criterio entre la DIAN y la parte actora. - Luego, no hay lugar a levantar la sanción. Ahora bien, aunque en el caso concreto no se presentó discusión sobre las cifras denunciadas, el artículo 647 del E.T. no solo exige que las cifras sean completas y verdaderas, también exige que los hechos con relevancia tributaria sean verdaderos. Por tanto, por el tema de la prueba, solo es pertinente levantar la sanción cuando, ante todo, se ha presentado una errónea apreciación del derecho o de diferencias de criterio entre la DIAN y la parte actora y, en virtud de esa errónea apreciación, el contribuyente declaró las cifras completas y verdaderas como hechos económicos con relevancia tributaria, cuando no tenían tal relevancia.

\section{9 de septiembre de 2011. Rad. 18413. Briceño de Valencia (No)}

Para el evento en estudio, como se expuso a lo largo de las consideraciones, no existe una norma que precise dónde debe entenderse realizada la actividad comercial y por ello, la jurisprudencia y la doctrina han adoptado criterios para resolver dicha duda, dando lugar a múltiples controversias sobre la territorialidad del ICA en el caso de que el declarante ejerza la citada actividad. Es entonces posible que el actor, por tener su domicilio principal en Cota y efectuar algunas actividades que hicieron posibles sus ventas, haya interpretado que la actividad comercial que dio origen a los ingresos gravados se hubiera llevado a cabo en dicho municipio, si se considera que QUINTEC declaró y tributó por ICA sobre los valores que consideró gravados en ese municipio, lo que demuestra la ausencia de intención fraudulenta con el fisco. Lo anterior hace ver que para la actora, como lo argumentó en la demanda, el domicilio comercial de su empresa se encuentra en Cota, lugar donde está establecida la sociedad, y es allí donde debe tributar, mientras que para la entidad demandada, la jurisdicción del tributo se encuentra en el Distrito Capital, lugar donde se materializan efectivamente las ventas de mercancía y por tanto, se realiza la actividad comercial, y que, aunque ésta última sea la posición correcta de acuerdo con las pruebas aportadas, las dos constituyen interpretaciones válidas para efectos de que se configure la diferencia de criterios y por tanto, no sea procedente la sanción por inexactitud, dado que, además, los hechos y cifras que aparecen declarados son completos y verdaderos.

16 de septiembre de 2011. Rad. 17777. Ortiz de Rodríguez (Sî)

La Sala reitera que la sanción prevista en el artículo 647 del E.T. se impone cuando se omiten ingresos, se incluyen costos, deduc- 
ciones, descuentos, exenciones, pasivos, impuestos descontables, retenciones o anticipos inexistentes, que ocasionen un menor impuesto a pagar o un mayor saldo a favor. En el caso que se analiza se da el supuesto fáctico señalado como quiera que incluir mayores valores a los que corresponden por concepto de impuestos descontables, origina un mayor saldo a favor. Dado que la indebida apreciación de los hechos impidió su adecuación a las normas en las cuales pretendía ampararse el contribuyente y a que dichos preceptos, artículos 107 y 488 del Estatuto Tributario, les quiso dar un alcance que el legislador no autorizó, la Sala considera que se configuran los supuestos de hechos contemplados en el artículo 647 del E.T. para imponer la sanción.

\section{8 de julio de 2011. Rad. 17161. Ortiz de Rodríguez,(Sí)}

La declaración de la deducción por amortización de las inversiones correspondientes a la rehabilitación de la línea de tubería Tibitoc-Casablanca, derivó un menor saldo a pagar producto de un beneficio inexistente, lo cual configura inexactitud sancionable en los términos del artículo 647 del Estatuto Tributario. Al tenor de dicha norma, son hechos sancionables la omisión de ingresos, de impuestos generados por las operaciones gravadas y de bienes o actuaciones susceptibles de gravamen, la inclusión de costos, deducciones, descuentos, exenciones, pasivos, impuestos descontables, retenciones o anticipos inexistentes, y, en general, la utilización en las declaraciones tributarias, o en los informes suministrados a las oficinas de impuestos, de datos o factores falsos, equivocados, incompletos o desfigurados, de los cuales se derive un menor impuesto o saldo a pagar o un mayor saldo a favor para el contribuyente o responsable. No hay lugar a imponer sanción por inexactitud cuando el menor valor a pagar que resulte en las declaraciones tributarias se derive de errores de apreciación o de diferencias de criterio entre las oficinas de impuestos y el declarante, relativos a la interpretación del derecho aplicable, siempre que los hechos y cifras denunciados sean completos y verdaderos. Sin duda alguna, la amortización examinada constituye una deducción inexistente que aminoró la tributación y cuya declaración no provino de diferencias de criterio en la interpretación del derecho aplicable. De manera que por este aspecto tampoco se desvirtuó la legalidad de los actos demandados, lo que conduce a confirmar la sentencia apelada en su integridad.

\section{9 de mayo de 2011. Rad. 18039. Briceño de Valencia (Sí)}

Para la Sala, la sanción por inexactitud se debe mantener frente a las partidas que no se aceptaron, pues el rechazo no obedeció a una diferencia de criterios en torno a la interpretación del derecho aplicable, ya que el artículo 107 del Estatuto Tributario es claro en señalar los requisitos para que un gasto se tenga como expensa necesaria, y no puede calificarse como diferencia de criterios en la interpretación de esta norma la apreciación particular de cada uno de los hechos que originaron las partidas o gastos rechazados, para atribuirles la naturaleza de las deducciones procedentes, o la falta de prueba del cumplimiento de los requisitos consagrados en la norma. La Sala había considerado de manera reiterada que ni por controversias de interpretación, ni por falta de pruebas era pertinente aplicar la sanción. 
Que si los rechazos obedecían a falta de prueba -contable o no-o a defectos formales en su comprobación debía hacerse un examen analítico y probatorio y establecerse la falsedad, inexistencia, simulación, etc., de los costos, gastos y demás partidas objeto de glosa oficial, puesto que, entre otros, la sanción estaba prevista en el evento de que el contribuyente solicitara costos, deducciones, pasivos, etc. en los que no hubiera incurrido efectivamente, de los cuales derivara un menor impuesto a pagar o un mayor saldo a favor. Sin embargo, la jurisprudencia reciente de la Sala ha señalado que la falta de prueba sobre la realidad y procedencia de las partidas declaradas no es motivo para no aplicar la sanción por inexactitud.

\section{5 de mayo de 2011. Rad.17306. Bastidas Bárcenas (Sî)}

Sin embargo, la Doctrina Judicial reciente de la Sala ha tenido por criterio que la falta de prueba sobre la realidad y procedencia de las partidas declaradas no es motivo para no aplicar la sanción por inexactitud. En efecto, en sentencia del 28 de junio de 2010, la Sala consideró que la falta de prueba sobre la realización de los costos, significaba la inclusión en la declaración de costos inexistentes que daban lugar a un menor impuesto a pagar, conducta que era sancionable en virtud del artículo 647 del Estatuto Tributario. Así mismo, mediante sentencia del 19 de agosto de 2010, la Sala señaló que generaba la sanción por inexactitud la conducta del contribuyente de incluir en la declaración, como deducciones, partidas frente a las cuales no se demostró su realidad y procedencia, que afectaron la base gravable y dieron lugar a un menor impuesto a cargo. En esa oportunidad advirtió que no era necesario que la Admi- nistración estableciera que los gastos fueron irreales, pues lo cierto era que fueron solicitados como deducción, sin demostrar su procedencia; máxime cuando correspondía al contribuyente desvirtuar la presunción de legalidad de los actos administrativos. Posteriormente, en el caso fallado en la sentencia del 14 de octubre de 2010, la Sala estableció que ni en sede administrativa ni judicial la sociedad demandante había logrado respaldar contablemente la existencia de un pasivo registrado en la cuenta PUC 2355, no obstante el requerimiento de la DIAN. Que en ese contexto, se concluía que, de conformidad con el artículo 647 del E.T., era procedente la sanción por inexactitud impuesta por la DIAN, por haberse incluido en la declaración pasivos inexistentes. La anterior posición jurisprudencial guarda correspondencia con la sentencia C-571 de 2010 por medio de la cual, la Corte Constitucional declaró la exequibilidad de la expresión "datos o factores falsos, equivocados, incompletos o desfigurados" contenida en el artículo 647 del Estatuto Tributario. En efecto, a juicio de la Sala, para que una partida declarada se tenga como real y verdadera, como regla general, debe probarse la realización de la misma, que existe, que fue efectuada. Es decir, requiere de una actividad probatoria suficiente y adecuada sobre la existencia de esos hechos que originan la partida. Para la Sala la sanción por inexactitud no tiene como condición que se evidencie una conducta evasiva o fraudulenta por parte del contribuyente, pero si se requiere que los datos declarados sean reales. En este sentido, la Sala comparte el criterio de la parte demandada cuando considera que ante la falta de demostración de los costos y deducciones declarados, da lugar a que se tenga como costos y deducciones inexistentes en la de- 
claración tributaria, con los cuales se derivó un mayor saldo a favor para la sociedad que da lugar a la sanción por inexactitud. En consecuencia, se confirmara el numeral primero de la sentencia apelada que declaró no probadas las excepciones propuestas y se revocará en lo demás, para en su lugar negar las pretensiones de la demanda.

\section{5 de mayo de 2011. Rad. 17361. Ortiz de Rodríguez (Sî)}

No es procedente exonerar de la sanción a la demandante bajo el entendido de que incurrió en un error de interpretación de las normas y que, por lo tanto, se presentó una diferencia de criterios respecto de las mismas pues, en el caso concreto, la demandante incurrió en un error de interpretación de los hechos, aspecto este que no da lugar a exonerarse de la sanción por inexactitud. La Sala reitera que la sanción prevista en el artículo 647 del E.T. se impone cuando se omiten ingresos, se incluyen costos, deducciones, descuentos, exenciones, pasivos, impuestos descontables, retenciones o anticipos inexistentes, que ocasionen un menor impuesto a pagar o un mayor saldo a favor. Asimismo, debe entenderse el adjetivo inexistente en sus dos acepciones: como relativo a aquello que carece de existencia y como relativo a aquello que, si bien existe, se considera totalmente nulo porque es falto de valor y fuerza para obligar o tener efecto, por ser contrario a las leyes, o por carecer de las solemnidades que se requieren en la sustancia o en el modo. Es esa la razón para que el artículo 647 del E.T. prevea que lo que se quiere sancionar, en general, es la utilización en las declaraciones tributarias, o en los informes suministrados a las oficias de impuestos, de datos o factores falsos, equivocados, incompletos o desfigurados, puesto que el significado de todos estos adjetivos implica la inexistencia de los valores que se consignan como costo, deducción, descuento, exención, pasivo, impuesto descontable, retención o anticipo sin que tengan esa calidad, ya sea porque en realidad no existen o porque, aun existiendo, no se probaron los requisitos que les de el efecto jurídico invocado.

También precisa la Sala que para imponer la sanción por inexactitud no se requiere probar que el contribuyente haya actuado con intención dolosa o culposa, pues la infracción se tipifica simplemente por la inclusión de los datos a que antes se hizo referencia, en la calidad pretendida. Por lo tanto, no le asiste razón a la demandante cuando precisa que para imponer la sanción por inexactitud, la autoridad tributaria debe probar que el contribuyente incluyó datos falsos con el ánimo de defraudar al Estado, pues, como se precisó, ese es tan solo uno de los hechos que tipifica la norma como infracción. No es necesario pues, que se compruebe el dolo con que actuó el contribuyente.

\section{5 de mayo de 2011. Rad. 17708. Briceño de Valencia $(\mathrm{S} \hat{\imath})$}

Pues bien, de acuerdo con lo anterior, la Sala considera que para que un factor de la declaración se tenga como real y verdadero, por regla general, debe probarse la realización del mismo, que existe, que fue efectuado. Es decir, requiere de una actividad probatoria suficiente y adecuada sobre la existencia de los hechos que originaron la partida o el concepto. Para la Sala la sanción por inexactitud no tiene como condición que se evidencie una conducta evasiva o fraudulenta por parte del contribuyente, pero sí se requiere que los datos declarados sean reales. 
En este caso, el rechazo de la deducción por salarios que se mantiene en esta decisión, se debe a la falta de prueba del pago de los aportes parafiscales sobre los pagos salariales, conforme con el artículo 108 del Estatuto Tributario, razón por la cual, la sanción es procedente. En relación con la adición de ingresos que en esta providencia también se mantiene, se debió a una omisión de ingresos por venta de divisas, debidamente probada por la DIAN, sin que se advierta una diferencia de criterios en torno a la interpretación del derecho aplicable. Lo que pretende la sociedad es que los ingresos se calculen con base en una disposición no aplicable al caso. En consecuencia, se mantiene la sanción por este concepto. Por lo anterior y teniendo en cuenta que se aceptaron las deducciones por gastos de arrendamiento e intereses y demás gastos financieros, se hará un nuevo cálculo de la sanción por inexactitud.

\section{4 de abril de 2011. Rad.17261. Bastidas Bárcenas (Sî)}

No resulta procedente exonerar de la sanción a la demandante bajo el entendido de que incurrió en un error de interpretación de las normas, pues, como se precisó, en el caso concreto, la demandante incurrió en un error de interpretación de los hechos, aspecto este que no da lugar a exonerarse de la sanción por inexactitud. La Sala reitera que la sanción prevista en el artículo 647 del E.T. se impone cuando se incluyen costos, deducciones, descuentos, exenciones, pasivos, impuestos descontables, retenciones o anticipos inexistentes. Y, que para que se perfeccione la infracción, la inclusión se debe ejecutar con el propósito de obtener un provecho que se traduce en el menor pago de impuestos o en la determinación de un mayor saldo a favor. Así mismo, reitera que el adjetivo inexistente debe entenderse en sus dos acepciones: como adjetivo relativo a aquello que carece de existencia; y como adjetivo relativo a aquello que, si bien existe, se considera totalmente nulo, porque es "Falto de valor y fuerza para obligar o tener efecto, por ser contrario a las leyes, o por carecer de las solemnidades que se requieren en la sustancia o en el modo". Ahora bien, la Sala también precisa que para imponer la sanción por inexactitud no se requiere probar que el contribuyente haya actuado con intención dolosa o culposa, pues la infracción se tipifica simplemente por la inclusión, por error de interpretación, de hechos económicos y de la subsunción de los mismos en la norma que se invoca para amparar el beneficio (infracción objetiva), o por la inclusión, de manera dolosa, de hechos falsos (infracción subjetiva). Por lo tanto, no le asiste razón al demandante cuando precisa que para imponer la sanción por inexactitud, la autoridad tributaria debe probar que el contribuyente incluyó datos falsos con el ánimo de defraudar al Estado, pues, como se advirtió, ese es tan solo uno de los hechos que tipifica la norma como infracción. No es necesario pues, que se compruebe el dolo con que actuó el contribuyente.

\section{1 de marzo de 2011. Rad. 16285. Ortiz de Rodríguez (Sî)}

La Sala considera que no se debe exonerar a la Corporación Deportiva Once Caldas, de la sanción por inexactitud, pues no se evidencia en el caso discutido una diferencia de criterio respecto del derecho aplicable, sino la omisión de ingresos, inclusión de deducciones y rentas exentas equivocados e inexistentes, conducta que tipifica la norma 
en cita como sancionable. La situación fáctica en el caso bajo análisis evidencia que la sanción por inexactitud se impuso como consecuencia de la adición de ingresos y el rechazo de deducciones y rentas exentas, proceder que se fundamentó en dos aspectos a saber: la errada contabilización y causación de los ingresos originados en la venta del jugador de futbol al equipo español Real Madrid; y el errado procedimiento para incluir deducciones y solicitar la renta exenta. De lo anterior se desprende que el mayor impuesto determinado en los actos acusados obedeció a la inclusión de factores equivocados e inexistentes en la declaración de la contribuyente que dio lugar a que la Administración modificara el correspondiente denuncio, por lo que se dan los supuestos de hecho que hacen procedente la aplicación sanción por inexactitud impuesta a la sociedad actora, que asciende a la suma de $\$ 4.868 .656 .000$.

\section{0 de marzo de 2011. Rad. 17667. Bastidas Bárcenas (Sî)}

No es pertinente exonerar de la sanción por el hecho de que se presentó diferencia de criterios en relación con las normas que se tuvieron en cuenta para resolver el caso, porque el cargo se despachó desfavorablemente en virtud de la falta de prueba. Y si bien las dudas provenientes de los vacíos probatorios pueden resolverse a favor del contribuyente; para que así sea, por una parte, debe estar plenamente establecido que no hay forma de eliminar las dudas y, por otra, sobre los hechos que se pretenden probar, el contribuyente no debe estar obligado a aportar la prueba, conforme así lo prevea el E.T. En ese contexto, la inexistencia a que alude el artículo 647 del E.T. está referida a la evidencia probatoria de que los costos, deducciones, descuentos, exenciones, pasivos, impuestos descontables, retenciones o anticipos, en realidad no se hicieron, o que habiéndose hecho, conforme se deduzca de ciertos medios probatorios, en el proceso no reposa la prueba conducente, pertinente y útil que dé cuenta de su cuantificación, o que estando probada la existencia y la cuantificación del egreso, ese egreso no se subsuma en ninguna norma que lo reconozca como costo, deducción, descuento, exención, pasivo, impuesto descontable, retención o anticipo, en virtud de la norma específica que les otorgue esa condición para ser invocado con fines tributarios.

\section{0 de marzo de 2011. Rad. 17492; 17366; 17549; 17703. Bastidas Bárcenas (Sî)}

No es pertinente exonerar de la sanción por el hecho de que se presentó diferencia de criterios en relación con las normas que se tuvieron en cuenta para resolver el caso, porque el cargo se despachó desfavorablemente en virtud de la falta de prueba. Y si bien las dudas provenientes de los vacíos probatorios pueden resolverse a favor del contribuyente; para que así sea, por una parte, debe estar plenamente establecido que no hay forma de eliminar las dudas y, por otra, sobre los hechos que se pretenden probar, el contribuyente no debe estar obligado a aportar la prueba, conforme así lo prevea el E.T. En ese contexto, la inexistencia a que alude el artículo 647 del E.T. está referida a la evidencia probatoria de que los costos, deducciones, descuentos, exenciones, pasivos, impuestos descontables, retenciones o anticipos, en realidad no se hicieron, o que habiéndose hecho, conforme se deduzca de ciertos medios probatorios, en el proceso no reposa la prueba conducente, pertinente y 
útil que dé cuenta de su cuantificación, o que estando probada la existencia y la cuantificación del egreso, ese egreso no se subsuma en ninguna norma que lo reconozca como costo, deducción, descuento, exención, pasivo, impuesto descontable, retención o anticipo, en virtud de la norma específica que les otorgue esa condición para ser invocado con fines tributarios.

Para la Sala, cuando el artículo 647 del E.T. se refiere a la interpretación del derecho aplicable, claramente se refiere a "la interpretación del derecho propiamente dicha" a que hace alusión la cita referida. El artículo 647 del E.T. no se refiere a la interpretación de los hechos. Por eso, no es posible exonerar de la sanción por inexactitud cuando el menor valor a pagar que resulte en las declaraciones tributarias, se derive de errores de hecho. Ahora bien, cuando el menor valor a pagar se derive de los errores de derecho en que incurra el contribuyente por indebida interpretación, el artículo 647 del E.T. exige que "los hechos y cifras denunciados sean completos y verdaderos". De manera que, así se advierta el "error de interpretación" que indujo al contribuyente a incluir en la declaración tributaria correspondiente erogaciones a título de costos, deducciones, descuentos, exenciones, pasivos, impuestos descontables, retenciones o anticipos, el contribuyente no está exonerado de probar la existencia de los hechos y cifras que declaró, pues ante la ausencia de esa prueba, igual se aplicará la sanción. No debe perderse de vista que las dudas provenientes de vacíos probatorios solo se resuelven a favor del contribuyente cuando no hay modo de eliminarlas y siempre y cuando el contribuyente no se encuentre obligado a probar determinados hechos. En ese contexto, habida cuenta de que la sanción por inexactitud prevista en el artículo 647 del E.T., como se precisó anteriormente, se tipifica cuando el contribuyente incluye en la declaración tributaria correspondiente impuestos descontables inexistentes; en aquellos casos en los que el demandante no probó la existencia de los descuentos alegados, la Sala decide mantener la sanción por inexactitud, pues, en estos eventos, pese a que para definir las glosas fue necesario establecer la interpretación de las normas citadas, de conformidad con el artículo 647 del E.T., el contribuyente sólo se exonera de la sanción cuando la interpretación le es desfavorable, pero demuestra que los hechos y las cifras denunciados son completos y verdaderos. En estos procesos, la interpretación fue favorable al demandante, pero no demostró, en algunos casos, la existencia de los hechos y las cifras denunciados.

\section{0 de febrero de 2011. Rad. 16887. Giraldo Giraldo (Sí)}

A juicio de la Sala, la decisión del Tribunal en cuanto levantó la sanción se modificará, pues el hecho de que en la legislación colombiana no exista una regulación especial de los contratos joint venture, no significa que, en este caso, las partidas rechazadas se hubieran derivado de diferencias de criterio en torno al derecho aplicable. En efecto, las deducciones por amortización de diferidos y del IVA en la adquisición de bienes de capital se rechazaron, no por la dificultad de interpretación de normas legales, sino por la ausencia de los presupuestos para su procedencia.

En el caso de la amortización, el rechazo se dio porque la actora no dio cumplimiento a lo previsto en el artículo 143 del Estatuto Tributario y al principio de causación y asociación de la deducción, y en el caso del IVA pagado en la adquisición de bienes de capi- 
tal, se rechazó porque no se trataba de bienes de capital sino de prestación de servicios, y no se daba cumplimiento al artículo 115-1 ibídem. En atención a lo anterior, como la actora incluyó en su declaración deducciones inexistentes que dieron lugar a un menor impuesto a pagar, sobre las mismas se debe liquidar la sanción por inexactitud.

\section{0 de de febrero de 2011. Rad. 17722. Giraldo Giraldo (Sí)}

En el caso bajo análisis no existen errores de apreciación o diferencias de criterio relativos a la interpretación del derecho aplicable. Por el contrario, se hace evidente el desconocimiento del derecho aplicable por parte de la demandante, al incluir en la declaración de renta glosada, deducciones que fueron cuestionadas por la administración no solo respecto a la prueba de su procedencia sino a los valores declarados. Una vez desvirtuada la presunción de veracidad de que gozan las liquidaciones privadas, se revierte la carga de la prueba, y, por lo tanto es al sujeto pasivo de la obligación a quien le corresponde desvirtuar los hechos que se le imputan.

La Sala observa que la sociedad contribuyente no aportó al proceso ningún elemento probatorio que sustente sus afirmaciones sobre el origen de las sumas declaradas, pues tanto en la vía gubernativa como en la jurisdiccional se limitó a alegar la procedencia de la deducción, sin aportar los medios de prueba respecto a la contabilización de los valores declarados en el renglón 73 "gastos por provisión de inventarios" ni la prueba de la alegada destrucción de inventarios. Contrario a lo señalado por el a quo, no se demostró ni la procedencia de la deducción ni su realidad contable, razón por la cual, ante la falta de veracidad del rubro declara- do, hay lugar a la imposición de la sanción por inexactitud, conforme al artículo 647 del Estatuto Tributario, por incluir en la declaración datos o factores incompletos o desfigurados, de los cuales se derivó un menor impuesto a pagar.

\section{9 de diciembre de 2010. Rad. 16420. Ortiz. de Rodríguez, (Sî)}

Con base en lo anterior y en vista de que el contribuyente solicitó un descuento tributario sin tener derecho a ello, por cuanto no demostró la calidad en los términos del artículo 25 del Código de Comercio, disminuyó el impuesto a su cargo, razón por la cual se configura una de las causales para hacerse acreedor a la sanción por inexactitud. No es válido alegar la existencia de diferencia de criterios, cuando lo que hizo el actor fue incumplir el claro mandato del artículo 1 del Decreto 890 de 1997 que reglamentó la Ley 218 de 1995, y que remite al artículo 25 del Código de Comercio. Tampoco es válido sostener que la interpretación errónea no da lugar a la sanción, pues, se insiste, el requisito que incumplió el actor, generaba, por mandato de las normas que regulan el beneficio, la improcedencia del mismo para el año 1998. Así las cosas, se ajustó a derecho la actuación de la DIAN, motivo suficiente para mantener la legalidad de la liquidación de revisión. En consecuencia, se impone revocar la sentencia apelada que anuló parcialmente el acto en mención, y, en su lugar, negar las pretensiones de la demanda.

\section{0 de diciembre de 2010. Rad. 17078. Briceño de Valencia (No)}

La Sala advierte que en este caso, la inexactitud en que incurrió la actora no obede- 
ció a la inclusión de datos o factores falsos, equivocados o incompletos, sino a una clara diferencia de criterio en la forma de determinar el valor comercial de la acción como parámetro para fijar un precio de enajenación no inferior al 25 por ciento señalado en el artículo 90 E.T.

\section{5 de noviembre de 2010. Rad. 16942. Bastidas Bárcenas (Sî)}

En el presente caso, el rechazo de las deducciones obedecieron [sic] al incumplimiento de los requisitos legales para su procedencia, como la falta de pago de los aportes parafiscales en el caso de los pagos salariales o la demostración del tipo de bien que se adquirió o que se actualizó o el tipo de actividad que se realizaría o realizó con esa adquisición, de manera que esa circunstancia, significó la inclusión en la declaración de renta de deducciones inexistentes $\mathrm{y}$ factores equivocados que derivaron un mayor saldo a favor de la contribuyente. De lo expuesto en este fallo, es evidente que los rechazos que se mantuvieron no obedecieron a una diferencia de criterios en torno a la interpretación del derecho aplicable. No puede calificarse como diferencia de criterios en la interpretación de una norma, la apreciación particular de cada uno de los hechos que originaron las partidas o gastos rechazados para atribuirles los efectos que las normas consagran. En consecuencia, sobre los conceptos rechazados se mantiene la sanción por inexactitud.

\section{1 de octubre de 2010. Rad. 16917. Ortiz de Rodríguez, (Sî)}

El legislador, en forma paralela a la consagración de cada uno de los deberes y las obligaciones tributarias, ha establecido un sistema de sanciones en el cual el defectuoso o total incumplimiento puede dar lugar a la comisión de la infracción tributaria y, por supuesto, a la imposición de la sanción. La imposición de sanciones implica que la Administración haya comprobado en un proceso previamente regulado, en los artículos 702 y siguientes del Estatuto Tributario, los supuestos sancionables que se endilgan; comprobación efectuada por los medios probatorios permitidos en la legislación tributaria, recogidos, controvertidos, debidamente analizados y valorados conforme a derecho, en las etapas de investigación, determinación y discusión del tributo, en las que al contribuyente se le garantiza el debido proceso. En el caso materia de litis, la Sala observa que el contribuyente incluyó en su declaración del impuesto sobre la renta y complementarios del año gravable 1998, exenciones inexistentes, lo que demuestra que se configura uno de los hechos sancionables previstos en el artículo 647 del Estatuto Tributario. Se advierte, que para la procedencia de la sanción por inexactitud no es necesario que la actuación del contribuyente le cause daño a la Administración, como lo anota el actor sino la comisión de la infracción. En esta forma, se ajustó a derecho la actuación de la Administración Tributaria, motivo suficiente para mantener la legalidad de la liquidación de revisión. En consecuencia, esta Corporación confirmará la decisión de primera instancia, que negó las súplicas de la demanda.

\section{7 de octubre de 2010. Rad. 16951. Ortiz de Rodríguez(No)}

De la actuación surtida en sede administrativa y ante esta jurisdicción, considera 
la Sala que procede el levantamiento de la sanción respecto al rechazo de la deducción por pagos no constitutivos de salario y de la deducción por diferencias en la base para el cálculo de los aportes parafiscales del salario integral, al presentarse una diferencia de criterios en torno al derecho aplicable, pues mientras el demandante ha sostenido que es la Ley la que permite que el patrono y sus trabajadores mediante acuerdos o contratos, pacten cuales pagos de los señalados en el artículo 128 del Código Sustantivo de Trabajo no son constitutivos de salario, la Administración ha considerado con base en la misma disposición que tales pagos son salarios porque debe haberse dispuesto expresamente, acordado convencional o contractualmente $\mathrm{u}$ otorgado en forma extralegal, es decir, el debate se concretó en la interpretación y alcance del artículo 18 del Código Sustantivo de Trabajo.

Igual situación se presentó en la aplicación del artículo 18 de la Ley 50 de 1990, por medio del cual se modificó el artículo 132 del mismo Código, a tal punto que el legislador tuvo que interpretar con autoridad con la expedición de la Ley 789 de 2002, habida cuenta que la ley generaba confusión. En consecuencia, esta Corporación modificará la decisión de primera instancia, que declaró la nulidad parcial de los actos administrativos demandados en lo que respecta al levantamiento proporcional de la sanción por inexactitud por las razones indicadas.

\section{6 de septiembre de 2010. Rad.16938. Giraldo Giraldo (Sî)}

Considera la Sala que están dados los presupuestos que le permiten concluir, como lo hizo el a quo, que se ha presentado una diferencia de criterios y que además no se con- figuraron los presupuestos establecidos en el artículo 647 del E.T. que hagan imperativa la imposición de la sanción por inexactitud, por cuanto los hechos y cifras denunciados por el contribuyente fueron completos y verdaderos. No prospera el cargo de la demandada.

\section{6 de septiembre de 2010. Rad. 17005. Giraldo Giraldo (Sí)}

Observa la Sala que el artículo 647 del Estatuto Tributario establece que constituye inexactitud sancionable en las declaraciones tributarias la omisión de ingresos, de impuestos generados por las operaciones gravadas, así como la inclusión de costos, deducciones, descuentos, exenciones, pasivos, impuestos descontables, retenciones o anticipos, inexistentes, y, en general, la utilización en las declaraciones tributarias de datos o factores falsos, equivocados, incompletos o desfigurados, de los cuales se derive un menor impuesto o saldo a pagar, o un mayor saldo a favor para el contribuyente o responsable.

En este caso la DIAN impuso la sanción por inexactitud sólo en relación con las retenciones rechazadas, la cual se mantendrá, pues no hay diferencia de criterios sino desconocimiento de las normas tributarias y contables que se citaron, pues la sociedad, sin fundamento legal, incluyó retenciones inexistentes en el período fiscal en el que las declaró, desconociendo que las normas claramente indican que en las declaraciones de renta se incluirán las retenciones que se practiquen en el ejercicio fiscal. Así las cosas, para la Sala los actos administrativos demandados se ajustaron a derecho, por lo que la sentencia apelada, que negó las pretensiones de la demanda, se debe confirmar. 
19 de agosto de 2010. Rad. 18485. Ortiz de Rodríguez, (Sî)

La sanción por inexactitud le fue impuesta, teniendo en cuenta que la actora no apropió sus utilidades conforme lo exige el artículo 211 del Estatuto Tributario, es decir no hubo capitalización de las utilidades o apropiación como reserva para la rehabilitación, extensión y reposición de los sistemas para tener derecho a la renta exenta; exención que no se extiende a los intereses moratorios recibidos por el pago inoportuno de los servicios públicos, para el caso acueducto y alcantarillado, por lo que debía imponerse la sanción por inexactitud, pues, la inclusión de una exención inexistente para ese año generó un menor impuesto a cargo.

La demandante considera que la aplicación de la sanción por inexactitud no es procedente porque el impuesto se liquidó conforme con una correcta interpretación de la ley. Se apoya en el artículo 647 inciso final del mismo ordenamiento, para sostener que no hay lugar a sanción por inexactitud cuando existe diferencia de criterio entre la Administración de impuestos y el contribuyente sobre el derecho aplicable.

De la lectura de esta disposición se deduce que la diferencia de criterio debe versar sobre el derecho aplicable, con la condición de que los hechos y cifras declarados sean veraces y completos. La controversia que se generó entre la Administración y la declarante no cumplió estos requisitos, En efecto, la diferencia se presentó entre un criterio jurídico fundado en la ley y un criterio personal, como lo indica el actor "mi poderdante por un criterio de interpretación de su contador no puede ser objeto de sanción por inexactitud", carente de respaldo legal. De otra parte los datos no fueron correctos porque el impuesto se liquidó por menor valor como consecuencia de la no aplicación de las normas pertinentes. En esta forma, se ajustó a derecho la actuación de la Administración Tributaria, motivo suficiente para mantener la legalidad de la liquidación de revisión.

\section{9 de agosto de 2010. Rad. 16948. Briceño de Valencia (No)}

En cuanto a la sanción por inexactitud esta Corporación considera que entre la DIAN y el contribuyente se dio una clara diferencia de criterios en relación con la interpretación y aplicación del artículo 121 literal a) ET. En efecto, la diferencia surgió por la forma como la demandante analizó en conjunto a operación de recepción y envío de giros y las labores de los corresponsales en el exterior, de las que derivó los pagos de las comisiones, todo lo cual le permitió entender que se trataba de una compraventa de divisas. En estas condiciones, se revocará la decisión apelada y, en su lugar, se anularán parcialmente los actos acusados. A título de restablecimiento del derecho, se levantará la sanción por inexactitud.

\section{9 de agosto de 2010. Rad. 16988. Giraldo Giraldo (Sî)}

La Sala confirmará la sanción por inexactitud impuesta en los actos oficiales, en razón a que el contribuyente incluyó en su declaración, como deducciones, partidas frente a las cuales no se demostró su realidad y procedencia, que afectaron la base gravable originando un menor impuesto a cargo, advirtiéndose que, contrario a lo que afirmó la demandante, no era necesario que la Administración estableciera que los gastos fueron irreales, pues lo cierto es que fueron 
solicitados como deducción, sin demostrar su procedencia; máxime cuando era a la actora a quien le correspondía desvirtuar la presunción de legalidad de los actos administrativos. Así las cosas, para la Sala los actos administrativos demandados se ajustaron a derecho, por lo que la sentencia apelada, que negó las pretensiones de la demanda, se debe confirmar.

\section{0 de junio de 2010. Rad.16889. Ortiz de Rodríguez,(Sî)}

Para la Sala la imposición de la sanción no está falsamente motivada, pues está demostrado que el actor sí incluyó en su declaración costos inexistentes y datos desfigurados de los cuales derivó un menor saldo a pagar. En efecto, en la respuesta al requerimiento especial, el contribuyente señaló que existieron algunos costos que no cumplieron con ningún requisito ni prueba del desembolso efectuado y declarado, entre los cuales señaló los correspondientes a la señora [...], es decir, reconoció que los costos por operaciones con la mencionada señora y con otros más no eran procedentes (folio 1537 c.a.). Además, el contribuyente pretendió soportar más costos de los declarados sin que tampoco estuvieran asociados a los ingresos del período gravable, cuando se ha debido limitar a probar sólo los costos declarados y que fueron cuestionados por la Administración. Para la Sala, no es claro el hecho de que se pretendan acreditar costos por valor superior al solicitado en la declaración, cuando precisamente el actor señala en la demanda (folio 261 c.ppal.) que no se podían incorporar para el año gravable discutido los costos y los ingresos correspondientes al contrato con [...] porque no se cumplió el objeto del mismo y tuvo la necesidad de demandar su cumplimiento. El actor tampoco aduce ningún elemento probatorio que acredite que los mayores costos soportados corresponden a ese contrato, salvo la solicitud de envío de la actuación ante el Juzgado 4 Civil del Circuito de Bogotá, que para la Sala es una prueba que no conduce a su demostración. Así las cosas, la Sala no encuentra desvirtuada la legalidad de la sanción por inexactitud, por lo que se mantendrá en esta instancia.

\section{9 de abril de 2010. Rad. 16886. Bastidas Bárcenas (No)}

La Sala considera que no es procedente la sanción porque en relación con los gastos por operaciones forward que no se aceptaron, es evidente que se deriva de diferencias de criterios sobre la interpretación de los artículos 121 y 122 del Estatuto Tributario, sobre los pagos al exterior que para el beneficiario no son ingresos de fuente nacional y su procedencia fiscal, en la medida en que no están sometidos a retención en la fuente. Esto impide considerar que las cifras del denuncio contengan datos o factores falsos, incompletos, equivocados o desfigurados y que proceda la sanción por inexactitud en virtud del artículo 647 del Estatuto Tributario. Y tampoco procede la sanción por los gastos vía [...] porque el hecho de que las operaciones carezcan de prueba no implica que los pagos fueran inexistentes o falsos o que provinieran de operaciones simuladas, que son las conductas que se sancionan según el artículo 647 del Estatuto Tributario. En efecto, si los rechazos obedecen a falta de prueba -contable o no- o a defectos formales en su comprobación debe hacerse un examen analítico y probatorio y establecerse la falsedad, inexistencia, simulación, etc., de los costos, gastos y demás partidas objeto 
de glosa oficial, puesto que entre otros, la sanción está prevista en el evento de que el contribuyente solicite costos, deducciones, pasivos, etc., en los que no haya incurrido efectivamente de los cuales derive un menor impuesto a pagar o un mayor saldo a favor.

\section{5 de marzo de 2010. Rad.16715. Giraldo Giraldo (Sî)}

Para la Sala la imputación de un saldo a favor del período anterior que no corresponda a la realidad, sí es un factor desfigurado o equivocado que da lugar a un mayor saldo a favor, como aconteció en este caso. La actora presentó la declaración de renta de 1998 el 20 de abril de 1999 y para esa fecha el saldo a favor del impuesto de renta de 1997 era el determinado en la corrección presentada el 17 de noviembre de 1998 por \$278.163.000. La corrección que se declaró inválida y que arrojaba el saldo a favor que trasladó a la declaración de 1998, fue presentada el 28 de abril de 1999, es decir, con posterioridad a la imputación, de manera que este sólo hecho genera inexactitud sancionable. Ahora bien, aunque se tomara en cuenta la corrección de 28 de abril de 1999 como sustento del traslado del saldo a favor a la declaración de renta de 1998, este saldo a favor tampoco era correcto, pues la corrección que lo determinó fue declarada inválida por la DIAN, de manera que no podía imputarse en la declaración de renta de 1998. Este hecho, a juicio de la Sala, no evidencia una diferencia de criterios como eximente de la sanción, pues el error de apreciación en cuanto a las formalidades o procedimientos que se debían cumplir para corregir la declaración de renta y optar por beneficio de auditoría, si se llegó a presentar, lo fue en la actuación administrativa que dio por no válida la corrección a la declaración de renta de 1997 y no en esta actuación.

\section{5 de marzo de 2010. Rad. 17002. Bastidas Bárcenas (Sí)}

Por último, en relación con la sanción por inexactitud, la Sala en anteriores oportunidades ha establecido que "no se configura inexactitud, cuando el menor valor a pagar se derive de errores de apreciación o de diferencias de criterio entre las oficinas de impuestos y el declarante, relativos a la interpretación del derecho aplicable, siempre que los hechos y cifras denunciados sean completos y verdaderos". Como en el sub examine la demandante no incluyó los valores por cuenta de los ingresos percibidos por la venta de las acciones, es evidente la procedencia de la sanción por inexactitud que le fue impuesta por exclusión de ingresos, dado que, como se vio, la mencionada exclusión no era procedente.

\section{8 de marzo de 2010. Rad. 16652. Giraldo Giraldo (Sí)}

Considera la Sala que frente a las ganancias de capital por la venta de acciones del Banco República de Venezuela, la DIAN reconoció en la resolución del recurso de reconsideración que existe una clara diferencia de criterios entre la Administración y el contribuyente, razón por la cual se debía levantar. Sin embargo, se advierte que tal decisión no se evidenció al momento de determinar la sanción por inexactitud. Como el Tribunal aceptó que las ganancias de capital por la venta de las mencionadas acciones eran rentas exentas liquidó la sanción por inexactitud sólo en relación con el rechazo de la deducción por la venta de cartera que mantuvo. La 
sanción por inexactitud la liquidó en [...] que sumada a la sanción liquidada privadamente por [...] arrojó un total de sanciones por [...]. Ahora bien, el demandante considera que no hay lugar a mantener la sanción por la venta de cartera, pues el hecho de la pérdida es cierto y verdadero, de manera que su desconocimiento obedece a simples motivos de improcedencia que no son sancionables. Conforme al artículo 647 del Estatuto Tributario constituye inexactitud sancionable la utilización en la declaración de renta de datos o factores equivocados, incompletos o desfigurados de los cuales se derive un menor impuesto para el contribuyente. Como en este caso la sociedad solicitó como deducción la pérdida en la enajenación de cartera, que si bien, puede ser cierta y existente, fue un factor equivocado que dio lugar a un mayor saldo a favor. Esta conducta es sancionable con inexactitud.

\section{8 de marzo de 2010. Expediente 16729. Briceño de Valencia (No)}

En concordancia, se practicará nueva liquidación para rechazar los gastos por recuperación de cartera en cuantía de [...], y se levantará la sanción por inexactitud que se aplicó respecto de éstos, porque la jurisprudencia ha señalado que cuando el motivo de la desestimación de los costos, deducciones, descuentos o pasivos obedece a la falta de prueba, ello no implica que el respectivo rubro sea inexistente o falso, o que provenga de operaciones simuladas. También ha dicho que cuando los rechazos obedecen a falta de prueba -contable o no- o a defectos formales en su comprobación, debe hacerse un examen analítico y probatorio y establecerse la falsedad, inexistencia o simulación de los costos, gastos y demás partidas objeto de glosa oficial, puesto que la sanción está prevista, entre otros eventos, para cuando el contribuyente solicite costos, deducciones o pasivos, etc., en los que no haya incurrido efectivamente.

\section{4 de marzo de 2010. Rad.16531. Bastidas Bárcenas (No)}

No le asiste razón a la Administración en cuanto impuso sanción por inexactitud, pues la conducta desplegada por el actor no encaja en las previsiones de la norma transcrita, ni existe prueba dentro del expediente de que los costos solicitados fueran inexistentes. No debe perderse de vista que si las sanciones son de interpretación restrictiva, éstas deben aplicarse exactamente al hecho imputado. De manera que la circunstancia de no haber sido allegados los soportes contables, no constituye prueba que permita afirmar que los respectivos costos fuesen equivocados o correspondieran a conceptos inexistentes, o que el actor hubiese consignado en su denuncio factores incompletos o desfigurados que disminuyeran el impuesto a cargo o que aumentaran el saldo a favor.

\section{2 de febrero de 2010. Rad. 17410. Briceño de Valencia (Sî)}

En efecto, el aludido principio jurídico significa que no es posible imponer doble sanción respecto de un mismo hecho, de forma tal que al derivarse la sanción de hechos diferentes, respecto de cada uno la ley establece válidamente una penalización separada. De una parte, el legislador establece en el artículo 670 del Estatuto Tributario los supuestos de hecho que dan lugar a la sanción por improcedencia de la devolución o compensación, así como, el procedimiento 
para su imposición [...]. De otra parte, en forma separada y mediante procedimiento distinto, el artículo 647 de la misma compilación fiscal expone los parámetros relativos a la sanción por inexactitud, derivada de una conducta diferente del contribuyente, por cuanto, procede por haber registrado voluntariamente en sus declaraciones tributarias con ostensible desconocimiento de las leyes fiscales datos incompletos, inexactos, equivocados o no ajustados a las exigencias contables y tributarias. Es claro entonces que no se sanciona dos veces al contribuyente por el mismo hecho, toda vez que mientras la sanción por inexactitud se impone como consecuencia de un proceso de determinación del impuesto y obedece al hecho de haber omitido ingresos, solicitado descuentos improcedentes o detraído partidas no deducibles o sin el correspondiente soporte su denuncio tributario, la sanción por improcedencia de las devoluciones o compensaciones deviene del hecho de haber solicitado y obtenido un saldo a favor el que a la postre resulta que no tenía derecho, además de existir, para su aplicación, dos procedimientos puntuales establecidos en normas independientes.

\section{8 de enero de 2010. Rad. 17032. Briceño de Valencia (Sí)}

En cuanto a la sanción por inexactitud ésta se configura por haber excluido de la base para liquidar la renta presuntiva una partida improcedente derivando de esto un menor valor a pagar y generando en su lugar un saldo a favor que no correspondía, situación tipificada como causal sancionable en el artículo 647 del Estatuto Tributario, además de impetrar una supuesta diferencia de criterio sobre la interpretación del artículo 189 del
Estatuto Tributario. Es obvio que al detraer de la base para la renta presuntiva el contribuyente en su declaración valores a los que no tiene derecho por expresa disposición legal, incluye en su declaración datos o factores equivocados, de los que desde luego, se deriva un menor impuesto del que ha debido determinarse, no siendo aceptable que se confunda el no acatamiento de un texto normativo vigente, con una diferente interpretación del "Derecho Aplicable", como ocurre para el evento en estudio, en el que no se cumple la exigencia del artículo 189 E.T. para que proceda la disminución de la base para determinar la renta presuntiva.

\section{6 de marzo de 2009. Rad.15962. Bastidas Bárcenas (No)}

También se levanta la sanción en relación con la pérdida en la enajenación de la cartera de ECOPETROL cuya deducción no se aceptó, pues, su rechazo se debe a la diferencia de criterios sobre la naturaleza de la transacción y de su procedencia frente al objeto de la actora que impide considerar que las cifras del denuncio contengan datos o factores falsos, incompletos, equivocados o desfigurados y que proceda la sanción por inexactitud en virtud del artículo 647 del Estatuto Tributario, por lo que en este aspecto se modificará la sentencia apelada.

\section{7 de septiembre de 2007. Rad. 15299. Palacio Hincapié (No)}

En cuanto a la ilegalidad de la sanción por inexactitud declarada por el Tribunal y que motivó el recurso de apelación de la entidad demandada, la Sala comparte la posición del Tribunal, en cuanto considera improcedente la sanción por inexactitud impuesta en el 
acto acusado, pues del análisis a los cargos propuestos se infiere que la actora no incurrió en los supuestos previstos en el artículo 647 del Estatuto Tributario. En efecto, se observa que las razones que tuvo la Administración para el rechazo de las deducciones responden a diferencias de criterio sobre el derecho aplicable, respecto de los pagos por concepto de indemnizaciones por accidentes de tránsito. Es así que no se ha cuestionado la realidad de los gastos declarados, sino su deducibilidad en los términos pretendidos por la actora.

\section{9 de abril de 2007. Rad. 14937. Romero}

\section{Díaz (No)}

Finalmente, en relación con la sanción por inexactitud, la Sala comparte la decisión del Tribunal, de que se configura diferencia de criterios sobre el derecho aplicable, como causal de exoneración (art. 647 [6] del Estatuto Tributario), porque los hechos y cifras denunciados son completos y verdaderos; y, el fundamento del rechazo de la renta exenta fue la interpretación que debe darse al artículo 211 del Estatuto Tributario.

\section{9 de noviembre de 2006. Rad. 15123. Ortiz Barbosa (Sî)}

Al respecto la Sala considera que dado que la sociedad no justificó el incremento patrimonial que se presenta entre los años de 1996 y 1997, que dio lugar a la determinación de la renta por comparación patrimonial, tipifica uno de los hechos para la imposición de la sanción, toda vez que el mayor valor de patrimonio líquido de una vigencia fiscal a otra, permite concluir una omisión de ingresos a través de rentas que han sido capitalizadas.
Ahora bien, no puede predicarse una diferencia de criterios entre la sociedad y las oficinas de impuestos para exonerarla de la sanción de inexactitud, como quiera que la Sala no encuentra que exista diversidad de criterios en cuanto al derecho aplicable, sino un claro desconocimiento de las normas tributarias que regulan el mecanismo para calcular la renta por comparación patrimonial, así como los conceptos fiscales que la desvirtúan.

\section{9 de noviembre de 2006. Rad. 15907. Palacio Hincapié (No)}

Lo expuesto evidencia que en efecto se presentó diferencia de criterios en cuanto al derecho aplicable, pues es claro que las partes, Administración y Contribuyente, interpretaron de manera diferente la ley en cuanto a la naturaleza jurídica de los ingresos derivados del contrato de cesión de derechos de publicidad.

Así las cosas se presentó causal de exoneración de la sanción, en los términos previstos en el artículo 647 del Estatuto Tributario, por estar demostrado, mediante la inspección contable, que los conceptos y valores declarados corresponden a la realidad del actor, sólo que, se reitera, que en su concepto el denominado contrato de cesión de derechos de publicidad, es de carácter comercial, y en consecuencia, los pagos originados en su ejecución, causan retención en la fuente bajo el concepto de servicios, y no de salarios, como es realmente y debió declararse.

\section{5 de octubre de 2006. Rad. 15282. López} Díaz (No)

Respecto a la sanción por inexactitud impuesta, la Sala comparte la decisión del a quo 
de levantarla, pues contrario a lo estimado por la entidad, encuentra viable aceptar la diferencia de criterios como causal de exoneración de la sanción, por estar dados los supuestos del inciso final del artículo 647 del Estatuto Tributario, según el cual, [...]

Según lo expuesto en los actos acusados y sus antecedentes, no se ha controvertido la realidad de la inversión realizada por el demandante, que fundamentó el descuento tributario solicitado en la declaración de renta, pues lo discutido es su calidad de empresa inversionista en los términos previstos por el legislador, para efectos de reconocerla fiscalmente.

Por tanto, el contenido y alcance de los beneficios tributarios contenidos en el artículo $5^{\circ}$ de la Ley 218 de 1995, respecto de sus destinatarios, suscitaron diversas interpretaciones, que motivaron doctrina de la DIAN (Concepto oficial 054168 de 9 de julio de 1998) y pronunciamiento de la jurisdicción contenido en la sentencia de diciembre 7 de 2000, todo lo cual pone en evidencia diferencias de interpretación frente a los preceptos legales, aspecto que exonera de la sanción de inexactitud.

Ahora bien, en cuanto al rechazo de los pasivos que originó la comparación patrimonial, la Sala observa que obedeció a deficiencias probatorias conforme a los presupuestos consagrados en el Ordenamiento Tributario, por lo que como lo ha sostenido la Sección en abundante jurisprudencia, cuando el motivo de la desestimación de determinados derechos o beneficios de orden fiscal, como costos, deducciones, descuentos o pasivos, obedezcan a la falta de prueba, contable o no, o al incumplimiento de requisitos formales, esto no implica que el respectivo ítem sea inexistente o falso o que proviniera de operaciones simuladas, según el primer inciso del artículo 647 del Estatuto Tributario, por lo que aunque resulte procedente su desconocimiento, no procede inexorablemente la imposición de la sanción por inexactitud.

\section{5 de octubre de 2006. Rad. 14514. Palacio Hincapié (No)}

Conforme lo anterior es claro que al no aceptarse el beneficio del descuento por las inversiones realizadas en empresas ubicadas en la zona de influencia del Río Páez, para aquellas personas naturales que no se constituyeron como empresa, y con un establecimiento de comercio, no se desconoció el derecho a la igualdad, pues las mismas están en situación diferente a aquellas empresas personas jurídicas, o personas naturales constituidas como tal, para efectos de acogerse a los beneficios citados, por tanto como fue voluntad del legislador conceder el beneficio del descuento solo a las empresas inversionistas y el demandante no tiene tal calidad, no es posible que reciba el mismo tratamiento.

En cuanto a la sanción por inexactitud, observa la Sala que tal como se indicó en primera instancia, se presentó una diferencia de criterio, la cual constituye causal de exoneración de la misma, más aún cuando no se ha controvertido por parte de las Oficinas de Impuestos la realidad de la inversión, sino la procedencia del beneficio del descuento en su calidad de persona natural.

\section{9 de octubre de 2006. Rad.15036. López} Díaz (No)

No procede la sanción por inexactitud puesto que se presentó una diferencia de criterios, la cual constituye causal de exoneración, toda vez que el objeto de discusión estuvo en la procedencia del beneficio del descuento en su calidad de persona natural 
no comerciante y no sobre la realidad de la inversión.

Además, el desconocimiento del contribuyente de los pronunciamientos doctrinales y jurisprudenciales acerca de la procedencia del beneficio, no es causal para la imposición de la sanción por inexactitud, pues dentro de las conductas descritas en el artículo 647 del Estatuto Tributario, no está prevista como sancionable.

\section{2 de octubre de 2006. Rad. 14749. Palacio Hincapié (No)}

Respecto de la sanción por inexactitud impuesta, la Sala comparte la posición del a quo, en cuanto considera que se configura una diferencia de criterios sobre el derecho aplicable, como causal de exoneración de la sanción en los términos del artículo 647 del Estatuto Tributario, pues como bien lo señala la actora, los hechos y cifras denunciados son completos y verdaderos, y el fundamento del rechazo de la renta exenta es la interpretación que debe darse a la norma aplicable (art. 211 E.T.).

Es así como sobre el citado precepto legal se han originado distintos pronunciamientos por parte de al entidad demandada, como son los plasmados en los Conceptos 071463 de 8 de agosto de 2001 y 018032 de 22 de marzo de 2002, que se citan en la liquidación oficial de revisión acusada. Además, no manifiesta la demandada en su recurso de apelación inconformidad alguna acerca de la sanción por inexactitud que fue levantada por el Tribunal.

\section{2 de agosto de 2006. Rad.15022. López Ligia (Sí)}

En cuanto a la sanción que se origina en el rechazo de las pérdidas fiscales la Sala no encuentra configurada la diferencia de criterios sobre el derecho aplicable, invocada por la actora, que consagra el artículo 647 del Estatuto Tributario como causal de exoneración. En consecuencia, se mantiene la sanción por inexactitud en la proporción que corresponde a la deducción rechazada.

Lo anterior, porque la discusión no versa sobre la oportunidad para solicitar las pérdidas como lo entiende la actora, sino sobre la viabilidad de la deducción, por haberse comprobado que la pérdida que se pretende absorbida por [...] en virtud de la fusión, era inexistente, hecho tipificado en el artículo 647 como sancionable.

\section{7 de julio de 2006. Rad. 14349. Palacio Hincapié (No)}

La Sala comparte la posición del Tribunal, en cuanto considera improcedente la sanción por inexactitud impuesta en el acto acusado, pues del análisis a los cargos propuestos se infiere que la actora no incurrió en los supuestos previstos en el artículo 647 del Estatuto Tributario.

En efecto, se observa que las razones que tuvo la Administración para el rechazo de las deducciones responden a diferencias de criterio sobre el derecho aplicable, como es la oportunidad para solicitar la deducción del gasto en el caso de las cuotas de Administración y las pérdidas originadas en la enajenación del activo fijo. Es así que no se ha cuestionado la realidad de los gastos declarados, sino su deducibilidad en los términos pretendidos por la actora. Sin embargo, se reliquidará la sanción por inexactitud teniendo en cuenta lo concerniente a los gastos de representación y pasajes, pues frente a ellos no se configura la diferencia de criterios que aduce el a quo para levantar la sanción. 
27 de octubre de 2005. Rad.14725. López

Ligia (No)

De conformidad con la norma antes transcrita, la diferencia de criterios debe versar sobre el derecho aplicable, siempre que los hechos y cifras declarados sean veraces y completos. En consecuencia, no hay diferencia de criterios cuando lo que se presenta es el desconocimiento del derecho procedente y cuando no son aplicadas las normas pertinentes.

Cuando la discrepancia entre el fisco y el contribuyente se basa en una argumentación sólida que, aunque equivocada, permita concluir que su interpretación en cuanto al derecho aplicable llevó al convencimiento que su actuación estaba amparada legalmente, existe una diferencia de criterios. No ocurre lo mismo, cuando se presentan argumentos que a pesar de su apariencia jurídica, no tienen fundamento objetivo y razonable.

El análisis que debe realizar el Juez para verificar si existe una verdadera diferencia de criterios busca determinar en cada caso, si el contribuyente obró o no con la creencia de que su actuar estaba amparado legalmente.

En la situación que se analiza hay elementos de juicio que permiten inferir el demandante obró de buena fe, pues los ingresos glosados fueron declarados efectivamente y se aportó el concepto de una autoridad lingüística reconocida, que evidencia las deficiencias en la redacción de la norma, de cuya simple lectura literal podría llegarse a la conclusión planteada por el contribuyente.

\section{3 de junio de 2005. Rad.14146. Palacio Hincapié (Sí)}

El parágrafo 2 del artículo 206 del Estatuto Tributario, es lo suficientemente claro al disponer que la exención del 30\%, no se otorgará sobre la porción de los ingresos excluida del impuesto de renta por otras disposiciones. Luego no habría ninguna razón para entender que la exención cubre los aportes obligatorios y voluntarios a los fondos de pensiones, que según el artículo 126-1 Ib., se señalan expresamente como ingresos no constitutivos de renta ni ganancia ocasional. Así que si bien no se configura inexactitud, cuando el menor valor a pagar se derive de errores de apreciación o diferencias de criterio entre las oficinas de impuestos y el declarante, relativos a la interpretación del derecho aplicable, no procede en el caso bajo análisis la exoneración de la sanción, pues el hecho de no incluir en la declaración la totalidad de las retenciones que "han debido efectuarse", no surge precisamente de una diferencia de criterios, sino mas bien del desconocimiento del derecho, pues ante la claridad de la norma no cabe interpretación distinta a la que se deduce de su tenor literal.

\section{3 de abril de 2005. Rad. 14279. Ortiz}

\section{Barbosa (Si)}

Impuestos pagados. En cuanto a la sanción por inexactitud no encuentra la Sala configurada la diferencia de criterios sobre el derecho aplicable prevista en el artículo 647 del Estatuto Tributario como causal de exoneración, además de que tampoco fue argumentada en la demanda y por el contrario, sí se hace evidente el desconocimiento del derecho aplicable, al incluir en su declaración de renta deducciones que por mandato legal son improcedentes, conducta que encaja dentro de las que define la norma como inexactitud sancionable, razón por la cual procede su confirmación, tal como lo decidió el a quo. 
3 de marzo de 2005. Rad.14281. Ortiz Barbosa (No)

En cuanto a la sanción por inexactitud la Sala comparte igualmente la decisión del Tribunal en el sentido de exonerar a la sociedad demandante de la misma, pues contrario a lo estimado por la apoderada de la entidad demandada, es posible evidenciar en el caso discutido una diferencia de criterios respecto del derecho aplicable, como causal de su exoneración de la sanción en los términos del artículo 647 del Estatuto Tributario.

En efecto, si bien es clara la norma al señalar como presupuesto de diferenciación entre activos fijos y activos movibles, su destinación a ser enajenados en el giro ordinario de los negocios, y desde el punto de vista fiscal, se considera independiente el tratamiento contable que por disposición legal deba darse a los "envases", como activos fijos, lo cierto es que ante tal previsión legal, la sociedad demandante contabilizó y declaró la pérdida de los envases dados de baja, en el entendido de que por su naturaleza habría lugar a la deducción por la perdida de tales bienes y es ahí donde radica la diferencia de criterios sobre el derecho aplicable. Circunstancia que hace improcedente la sanción por inexactitud impuesta. Se confirma entonces la sentencia apelada.

\section{3 de junio de 2004. Rad. 13225. Whittingham García (No)}

Aprecia la Sala que en el presente caso existió una diferencia de criterio sobre la interpretación del derecho aplicable, que exime a la actora de la imposición de la sanción por inexactitud, teniendo en cuenta que en efecto el pronunciamiento jurisprudencial ilustrativo del alcance de la expresión de la ley, evidencia la posibilidad de interpretaciones diversas de donde se colige que la decisión tomada por el Tribunal de instancia de levantar la sanción impuesta por la omisión de un factor de la base es correcta, por cuanto viene a ser aplicación de lo previsto en el último inciso del artículo 647 del Estatuto Tributario, que determina que no se configura inexactitud sancionable cuando el menor valor a pagar que resulte en las declaraciones tributarias, se derive de errores de apreciación o de diferencias de criterio entre las oficinas de impuestos y el declarante, relativas a la interpretación del derecho aplicable, siempre que los hechos y cifras denunciados sean completos y verdaderos.

\section{2 de abril de 2004. Rad.13935. López Ligia (Sî)}

$\mathrm{Al}$ respecto considera la Sala que le asiste razón a la demandada por cuanto como ya quedó establecido claramente, no podía solicitar la sociedad una deducción en el año 1996, por una terminación de actividad que ocurrió en el año siguiente. No se presenta entonces una diferencia de criterios entre la Administración y la contribuyente, sino una clara violación por la última del artículo 143 del Estatuto Tributario, por lo que al incluir una deducción inexistente para el año gravable de 1996, generó un menor impuesto a pagar, circunstancia que da lugar a imponer sanción por inexactitud. También comparte la Sala lo anotado por la demandada sobre el artículo 647 del E.T. ya que en este no se consagra factor alguno de proporcionalidad que permita graduar esta sanción, pues su liquidación se realiza con fundamento en los montos de los conceptos rechazados. Por estas razones, de acuerdo con el concepto del Ministerio Público, prospera el recurso inter- 
puesto por la demandada y en consecuencia la Sala revocará la sentencia impugnada y en su lugar denegará las súplicas de la demanda.

\section{9 de enero de 2004. Rad. 13582. Ortiz Barbosa (Sî)}

Oportunidad para la solicitud de pérdidas. En cuanto hace a la sanción por inexactitud, se observa que en la demanda se solicitó expresamente declarar que la sociedad actora no estaba obligada al pago de la sanción impuesta en los actos acusados, por lo que no puede aceptarse el argumento de la recurrente según el cual afirma excedió el Tribunal el petitum demandatorio al decidir sobre la misma. Sin embargo la Sala no encuentra razones para decretar por este aspecto la nulidad de los actos acusados, pues de una parte no se evidencian diferencias de criterio respecto del derecho aplicable, como causal de exoneración de la sanción, y por otra, no presenta la demandante razones que justifiquen el hecho de haber pretendido deducir en su declaración de renta del año 1996, una pérdida que por disposición expresa de la ley era improcedente. Así que se entiende configurada en el caso bajo análisis la inexactitud en los términos del artículo 647 del Estatuto Tributario.

\section{3 de diciembre de 2003. Rad. 13696.}

\section{López Díaz (No)}

En el presente caso, la Sala considera que se presentó diferencia de criterios respecto del derecho aplicable entre la Administración y la sociedad actora. Aunque no tuvo prosperidad el argumento presentado por la sociedad [...] para desvirtuar la adición de ingresos, existía una sustentación fuerte que permite concluir que su interpretación en cuanto al derecho aplicable aunque equi- vocado la llevó al convencimiento que su actuación estaba amparada legalmente, lo mismo se puede decir del cálculo de la deducción teórica, por lo que no es procedente la sanción por inexactitud y en consecuencia se confirmará la Sentencia del Tribunal en cuanto accedió a levantarla.

\section{2 de mayo de 2003. Rad. 13035. Ortiz Barbosa (No)}

Revisada la actuación surtida en sede administrativa y ante esta jurisdicción para la Sala es evidente que existe diferencia de criterio acerca del derecho aplicable (activos fijos - bienes de capital) por lo cual hizo bien el a quo al levantar la sanción por inexactitud.

\section{5 de mayo de 2003. Rad.13183. Ortiz. Barbosa (Sí)}

La controversia que se presentó entre la Administración y el demandante no cumplió estos requisitos. En efecto, la diferencia se presentó entre un criterio jurídico fundado en la ley y un criterio personal carente de respaldo legal, puesto que no es por una interpretación errada que gastos causados en un año fiscal se imputan a otro "por razones de orden práctico" como lo sostiene en abierta contradicción con los artículos 104 y 105 del Estatuto Tributario; que intereses moratorios u otros gastos que no tienen relación de causalidad con la actividad productora de la renta, al igual que sanciones impuestas por la Superintendencia de Sociedades los presente como expensas necesarias deducibles, con desconocimiento del artículo $107 \mathrm{ib}$. o se solicite como reducción el IVA pagado por la adquisición de bienes de capital para ser utilizados por otra sociedad y que por ello no guardan relación de causalidad con la actividad económica. 
Así las cosas el impuesto de renta que liquidó el contribuyente por un menor valor es consecuencia de la no aplicación de las normas pertinentes que son obligatorias y por ende no es de su arbitrio desconocerlas so pena de asumir las consecuencias previstas en la ley, por lo cual se hizo acreedor a la sanción por inexactitud.

\section{3 de julio de 2002. Rad. 12580. Ayala Mantilla (No)}

Por lo precedente, se comparte la decisión del tribunal en cuanto confirmó la legalidad de las glosas oficiales, que rechazaron la deducción solicitada por la sociedad actora en su declaración de renta relativa al año gravable de 1996, por cuanto se encontraba soportada en inversiones efectuadas en los años de 1981 a 1986, cuyo lapso para detraerlas era de cinco años, contados a partir de su realización y por ende, ampliamente vencidos para la fecha en se efectuó la absorción de la sociedad que incurrió en dichas erogaciones. De manera que es claro, que la deducción solicitada por la actora, era inexistente para el año gravable de 1996, por lo que debe mantenerse su rechazo.

Ahora bien, en relación con la sanción por inexactitud, la Sala comparte el concepto del Ministerio Público en cuanto no procede su imposición por tratarse de una diferencia de criterio sobre el derecho aplicable, tal como lo advirtió el Tribunal.

\section{3 de mayo de 2002. Rad. 12609. López Ligia (No)}

Esta Corporación comparte el criterio de la entidad demandada para rechazar la deducción de las donaciones realizadas por la sociedad actora en el año 1996, toda vez que las certificaciones aportadas por las Universidades beneficiarias no permiten acreditar el cumplimiento de los requisitos legales, por lo que deberá revocarse la sentencia impugnada.

En cuanto a la sanción por inexactitud impuesta por la Administración tributaria, se observa que existe una diferencia de criterios en torno al alcance del derecho aplicable, por lo que es procedente levantarla, de conformidad con lo dispuesto en el último inciso del artículo 647 del Estatuto Tributario.

\section{6 de abril de 2002. Rad. 12576. Palacio Hincapié (No)}

Donaciones Universidades. En relación con la sanción por inexactitud, impuesta la sociedad en cuantía de [...], la Sala considera cabalmente reunidas las previsiones contenidas en el inciso 2 del artículo 647 del ET, impeditivas de su aplicación, al tratarse de una verdadera diferencia de criterios en torno al derecho mismo y al alcance del aplicable.

\section{1 de febrero de 2002. Rad.12522. Ayala Mantilla (No)}

Beneficios fiscales concurrentes antes de la Ley 383 de 1997 (artículo 23). Por último levantará la sanción por inexactitud porque la inclusión del descuento en forma equivocada, evidentemente se originó en una diferencia de criterio al interpretar las normas jurídicas aplicables, lo cual está erigido en el artículo 647 del Estatuto Tributario, como eximente de la sanción.

\section{5 de junio de 2001. Rad. 11799. López Díaz (No)}

En el presente caso, no se presentó un desconocimiento del derecho, pues los datos 
suministrados fueron completos y veraces, presentándose el conflicto por la equivocada interpretación que la demandante hizo del artículo 354 del Estatuto Tributario, pero sobre un punto que revestía tal complejidad que resultaba posible caer en el error, además que la actora, con sus argumentos, deja en claro su convencimiento de haber actuado adecuadamente, al solicitar la deducción teórica, simultáneamente con la depreciación del ajuste por inflación.

\section{Derroteros fijados por la Sección Cuarta del Consejo de Estado}

De la jurisprudencia presentada se extrae:

3.1 Cuando exista la diferencia de criterios debe versar sobre el derecho aplicable, y tiene como requisito que los hechos y cifras declarados en la autoliquidación tributaria sean veraces y completos. Este es un hecho que se reconoce en la totalidad de las sentencias del Consejo de Estado.

3.2 La sanción por inexactitud es aplicable cuando exista prohibición expresa para la realización de una operación en el ámbito tributario, aunque existan normas que también resulten aplicables al caso, como ocurre en el traslado de pérdidas a los socios así se hubiera realizado en un proceso de fusión antes de la entrada en vigencia de la Ley 788 de 2002 (18485).

3.3 Para que se aplique la diferencia de criterios es necesario probar que la interpretación de las normas indujo al sujeto pasivo a apreciarlas de manera errónea. El autor de este documento se pregunta cómo se prueba esa circunstancia $(18485,18485)$.

3.4 No hay diferencia de criterios cuando no se hace una selección adecuada -de acuerdo con la realizada por el CE- de la norma aplicable a un caso particular, aunque exista duda razonable de la normatividad aplicable, toda vez que, no es aceptable confundir el desconocimiento de un precepto legal con la alegada diferencia de criterios en la interpretación del derecho aplicable (18807, 17450, 17708).

Para el CE no es un "error hermenéutico" la selección de la norma aplicable: la selección de una norma errada no es un problema de interpretación sino de inaplicación de la norma adecuada, motivo por el cual no son asuntos sobre los que se pueda configurar una diferencia de criterios.

3.5 La sanción por inexactitud es aplicable siempre que haya precedente jurisprudencial del rechazo del gasto -independientemente de aquel en que se haya basado para emitir la sentencia porque esa no es una preocupación para el CE-, porque en esos casos no hay diferencia de criterio (17786).

Con el pronunciamiento anterior se modifica la posición plasmada en la sentencia del Exp. 15036, según la cual el desconocimiento por parte de los sujetos pasivos de los pronunciamientos doctrinales y jurisprudenciales acerca de la normatividad no es causal para la imposición de la sanción por inexactitud, puesto que se considera que dentro de las conductas descritas en el artículo 647 del ET, no está previsto este supuesto como sancionable.

3.6 Siempre que las partes tengan claro en qué consisten los requisitos de necesidad, proporcionalidad y de relación de causalidad del artículo 107 del Estatuto Tributario, no se advierte que se presente diferencia de criterios cuando la discrepancia ocurra con motivo de la valoración de los hechos, que no puede ser distinta de la interpretación estricta del derecho aplicable (17786, 18039). 
3.7 La sanción por inexactitud puede ser confirmada en segunda instancia por el Consejo de Estado aun cuando en primera instancia se haya considerado que el demandante sujeto pasivo tenía razón en sus pretensiones (18485, 18341, 16420), y esta diferencia entre el Tribunal y el CE no configura diferencia de criterios, cuando se establezca por parte del Consejo de Estado que no hay prueba suficiente de lo alegado por el demandante (18341).

$\mathrm{El}$ autor de este documento considera que si el CE revoca la sentencia de primera instancia y no hay diferencia de criterios, entonces en primera instancia hubo prevaricato.

Con estas sentencias se cambia el derrotero según el cual, cuando existan pronunciamientos jurisprudenciales y administrativos -no solo de la DIAN sino de otras autoridades administrativas- dispares se configura la diferencia de criterios $(15282,13673,14749$, 14837, 9017).

3.8 Cuando la norma sea en detalle precisa y su desconocimiento no deje duda acerca de la responsabilidad del sujeto pasivo en la vulneración del ordenamiento, éste será sancionado con inexactitud, interesante supuesto de sanción que parte de un preconcepto del juzgador (18233, 17032, 16328, 15014, 14146, 13935, 12184, 5852).

3.9 Para imponer la sanción por inexactitud no se requiere probar que el contribuyente haya actuado con intención dolosa o culposa, pues la infracción se tipifica simplemente por la inclusión de los datos a que antes se hizo referencia, en la calidad pretendida (17361).

3.10 Para imponer la sanción de inexactitud no es necesario que la administración demuestre que se le ha ocasionado un daño o perjuicio (16917).

3.11 Constituye inexistencia de datos: (i) la ausencia de prueba de los mismos en la declaración; (ii) cuando aun probados, no se subsumen en ningún precepto jurídico del Estatuto Tributario que les dé valor y fuerza para tener el efecto invocado, por carecer de las solemnidades que exige ese Estatuto Tributario para darles la calidad de tales (18109, 17115, 17161, 17306, 18249, 17361, 17708, 17261, 16285, 17667, 17492, 17366, 17549, $17703,16887,17722,16942$ y 18341). Esta es la postura actual del CE.

Antes, no procedía la sanción aunque los pagos correspondieran a operaciones respecto de las cuales se carece de prueba -contable o no- o existen defectos formales en su comprobación porque debe hacerse un examen analítico y probatorio y establecerse la falsedad, inexistencia, simulación de los costos, gastos y demás partidas objeto de glosa oficial, porque esta circunstancia no implica que los pagos fueran inexistentes o falsos o que provinieran de operaciones simuladas, que son las conductas que se sancionan según el artículo 647 del Estatuto Tributario (16886, 16663, 16729, 17254, 15282, 12432, 2237, 2981, 1764), salvo los casos de las sentencias Rad. 10867 y 12184.

3.12 La sentencia del 1 de noviembre de 2012 (Rad. 18109 de Bastidas Bárcenas), tiene que ser comentada en un apartado especial. En esta providencia se configura la diferencia de criterios cuando se trate de "la interpretación del derecho propiamente dicha", cuando hay "un error de hermenéutica jurídica”, que consiste en aplicar la disposición pertinente a la controversia, pero dándole un sentido y alcance que no tiene. Si se trata de interpretación de los hechos no se configura la diferencia de criterios y será procedente la sanción por inexactitud.

En esta misma providencia, con sinceridad el Magistrado Bastidas advierte que "identi- 
ficar cuándo se está en presencia de un error de hermenéutica jurídica no es tarea fácil".

De tener acogida la forma de aplicación del artículo 647 propuesta en esta sentencia, el fallo dependerá en un grado máximo de la subjetividad del fallador, porque esta distinción es una propuesta vacía que se puede llenar con una decisión en cualquier sentido.

Un ejemplo favorable, cuestionable en todo caso, en el expediente 17078, el CE a pesar de modificar la declaración advirtió que la inexactitud en que incurrió la actora no obedeció a la inclusión de datos o factores falsos, equivocados o incompletos, sino a una clara diferencia de criterio en la forma de determinar el valor comercial de la acción como parámetro para fijar un precio de enajenación no inferior al 25 por ciento señalado en el artículo 90 E.T.

3.13 Hoy el contribuyente no está exonerado de probar la existencia de los hechos y cifras que declaró, pues ante la ausencia de esa prueba, igual se aplicará la sanción $(18109,18100,18249,18341,17306$, 17667, 17492, 17366, 17549, 17703, 17722, 16942, 16988).

Por el contrario, la carga de la prueba de la inexistencia de costos y gastos la tiene la Administración; así las cosas, la circunstancia de que el sujeto pasivo no allegue los soportes contables no constituye prueba que permita afirmar que los respectivos costos son equivocados o corresponden a conceptos inexistentes, o que el actor hubiese consignado en su denuncio factores incompletos o desfigurados que disminuyan el impuesto a cargo o que aumentaran el saldo a favor (16531, 12432, 2237, 2981, 1764), salvo el caso de la sentencia Rad. 10867.

3.14 En la determinación de la renta por comparación patrimonial, se tipifica uno de los hechos para la imposición de la sanción por inexactitud, toda vez que el mayor valor de patrimonio líquido de una vigencia fiscal a otra, permite concluir una omisión de ingresos a través de rentas que han sido capitalizadas $(15123,18329)$.

3.15 Para calcular la sanción de inexactitud se debe tener en cuenta la sobretasa del impuesto sobre la renta (18368).

3.16 Siempre procede la diferencia de criterios cuando la norma produzca diversas interpretaciones y éstas resulten razonables a juicio del juez contencioso administrativo. En ese contexto se somete a las partes a un acentuado criterio de discrecionalidad por parte del fallador, quien establecerá si la discrepancia entre el fisco y el sujeto pasivo parte de una argumentación sólida que aunque equivocada, permita concluir que su interpretación en cuanto al derecho aplicable le permitió creer que su actuación estaba amparada legalmente y no cuando se presentan argumentos que a pesar de su apariencia jurídica carecen de fundamento objetivo y razonable; de lo contrario, la jurisdicción considerará que hay un claro desconocimiento de las normas tributarias o del derecho procedente (Sí es razonable: 16951, 17432, 16779, 16867, 16537, 16956, 17390, 16340, 16165, 16766, 16054, 15839, 15299, $14937,15907,15282,14514,15036,14349$, 14251, 14803, 14725, 14837, 14928, 13873, 14281, 14575, 14396, 13225, 13935, 13582, 13696, 13493, 12450, 13035, 12930, 12432, 12698, 12576, 12522, 12373, 11799, 9951, $9119,8592,8721,8706,8542,8090$. No es razonable: $17005,17432,17270,17032$, $16527,16328,15123,15014,15022,14279$, 13183, 10867, 12184, 7158, 5998).

3.17 Aunque hay cuatro pronunciamientos en este sentido, vale la pena traer su contenido por lo cándido que resulta para levantar la sanción por inexactitud: en efecto de lo ex- 
presado por las partes en las intervenciones realizadas a través del proceso gubernativo y ante la jurisdicción, se evidencian posiciones distintas (16938, 14928, 14396, 16948).

$3.18 \mathrm{La}$ sanción por inexactitud procede siempre que no se hayan incluido ingresos en la declaración tributaria, aunque tal comportamiento - la no inclusión- obedezca a una diferencia de criterios, incluso en la normatividad aplicable (18807, 16755, 17002, 7490); salvo el caso en que se considere que la diferencia de criterios está en la calidad o no de sujeto pasivo del impuesto (17362, 13301).

3.19 La sanción por inexactitud no es consecuencia directa del desconocimiento por parte de la Administración o del Juez Contencioso Administrativo de costos, gastos, deducciones, descuentos, exenciones, no sujeciones; siempre que los hechos y cifras denunciados por el sujeto pasivo sean completos y verdaderos, y la actuación del sujeto pasivo obedezca a una interpretación razonable del ordenamiento $(16779,16867$, 16537, 16956, 17390, 16340, 16165, 16766, $16054,15839,15299,14937,15907$, $15282,14514,15036,14349,14251$, $14803,14725,14837,14928,13873$, $14281,14575,14396,13225,13935$, $13582,13696,13493,12609,12522$, $12580,12450,13035,12930,12432$, $12698,12576,12522,12373,11799,9951$, $9119,8592,8721,8706,8542,8090)$.

3.20 En lo que atañe con la imposición de la sanción por inexactitud no existe la posibilidad de aplicar factor alguno de proporcionalidad que permita graduar esta sanción, toda vez que el artículo 647 del E.T. no lo consagra (13935).

3.21 La deducción de impuestos diferentes a los autorizados en el artículo 115 es causal de inexactitud (17777).
3.22 En relación con el non bis in idem, la inexactitud es compatible con otras sanciones, como la sanción por improcedencia de la devolución o compensación, toda vez que no se sanciona dos veces al sujeto pasivo por el mismo hecho (17410).

3.23 No sirve como mecanismo para desvirtuar la sanción por inexactitud, una vez se han desconocido costos o gastos por la Administración, soportar más costos de los declarados, porque se debe limitar a probar solo los costos declarados y que fueron cuestionados por la Administración (16889).

3.24 La imputación de un saldo a favor del período anterior que no corresponda a la realidad es un factor desfigurado o equivocado que da lugar a la procedencia de la sanción por inexactitud, así ese saldo a favor imputado sea declarado improcedente por la Administración con posterioridad a la presentación de la declaración por la que se impone la inexactitud (16715).

3.25 En el caso de la determinación del impuesto sobre la renta por renta presuntiva, se configura inexactitud por excluir del patrimonio una partida improcedente, derivando de esto un menor valor a pagar o un mayor saldo a favor, toda vez que a juicio del Consejo de Estado el artículo 189 del Estatuto Tributario es claro, motivo por el cual tal comportamiento constituye la inclusión en la declaración de datos o factores equivocados (17032).

3.26 Para el caso puntual de la deducción de la pérdida en la enajenación de cartera, en la medida en que no sea procedente, se considera un factor equivocado y es una conducta sancionable con inexactitud (16652), sin perjuicio de que en otros casos se considere que no es procedente la sanción (15962). 